\title{
Evidence-based clinical practice guidelines for liver cirrhosis 2015
}

\author{
Hiroshi Fukui ${ }^{1,2} \cdot$ Hidetsugu Saito $^{2} \cdot$ Yoshiyuki Ueno $^{2} \cdot$ Hirofumi Uto $^{2}$. \\ Katsutoshi Obara $^{2}$ - Isao Sakaida ${ }^{2}$ - Akitaka Shibuya ${ }^{2} \cdot$ Masataka Seike $^{2}$. \\ Sumiko Nagoshi ${ }^{2} \cdot$ Makoto Segawa $^{2}$ - Hirohito Tsubouchi ${ }^{2} \cdot$ Hisataka Moriwaki ${ }^{2}$. \\ Akinobu Kato $^{2}$ - Etsuko Hashimoto ${ }^{2}$ Kojiro Michitaka ${ }^{2}$ Toshikazu Murawaki ${ }^{2}$. \\ Kentaro Sugano $^{2} \cdot$ Mamoru Watanabe $^{2} \cdot$ Tooru Shimosegawa $^{2}$
}

Received: 12 April 2016/Accepted: 12 April 2016/Published online: 31 May 2016

(C) Japanese Society of Gastroenterology 2016

\begin{abstract}
The Japanese Society of Gastroenterology revised the evidence-based clinical practice guidelines for liver cirrhosis in 2015. Eighty-three clinical questions were selected, and a literature search was performed for the clinical questions with use of the MEDLINE, Cochrane, and Igaku Chuo Zasshi databases for the period between 1983 and June 2012. Manual searching of the latest important literature was added until August 2015. The guidelines were developed with use of the Grading of Recommendations Assessment, Development, and Evaluation (GRADE) system. This digest version in English introduces selected clinical questions and statements related to the management of liver cirrhosis and its complications. Branched-chain amino acids relieve hypoalbuminemia and hepatic encephalopathy and improve quality of life. Nucleoside analogues and peginterferon plus ribavirin combination therapy improve the prognosis of patients with hepatitis B
\end{abstract}

The original version of this article appeared in Japanese as

"Kankouhen Shinryo Guidelines 2015" from the Japanese Society of Gastroenterology (JSGE), published by Nankodo, Tokyo, 2015.

Please see the article on the standards, methods, and process of developing the guidelines (doi:10.1007/s00535-014-1016-1).

The members of the Guidelines Committee are listed in the "Appendix" in the text.

Hiroshi Fukui

hfukui@naramed-u.ac.jp

1 Department of Gastroenterology, Endocrinology and Metabolism, Nara Medical University, 840 Shijo-cho, Kashihara-shi, Nara 634-8522, Japan

2 Guidelines Committee for creating and evaluating the "Evidence-based clinical practice guidelines for liver cirrhosis", Japanese Society of Gastroenterology (JSGE), K18 Building 8F, 8-9-13, Ginza, Chuo, Tokyo 104-0061, Japan virus related liver cirrhosis and hepatitis $\mathrm{C}$ related compensated liver cirrhosis, respectively, although the latter therapy may be replaced by direct-acting antivirals. For liver cirrhosis caused by primary biliary cirrhosis and active autoimmune hepatitis, urosodeoxycholic acid and steroid are recommended, respectively. The most adequate modalities for the management of variceal bleeding are the endoscopic injection sclerotherapy for esophageal varices and the balloon-occluded retrograde transvenous obliteration following endoscopic obturation with cyanoacrylate for gastric varices. Beta-blockers are useful for primary prophylaxis of esophageal variceal bleeding. The $\mathrm{V}_{2}$ receptor antagonist tolvaptan is a useful add-on therapy in careful diuretic therapy for ascites. Albumin infusion is useful for the prevention of paracentesis-induced circulatory disturbance and renal failure. In addition to disaccharides, the nonabsorbable antibiotic rifaximin is useful for the management of encephalopathy. Anticoagulation therapy is proposed for patients with acute-onset or progressive portal vein thrombosis.

Keywords Liver cirrhosis · Diagnosis · Nutritional therapy · Antiviral therapy · Nonviral cirrhosis · Gastroesophageal varices · Ascites · Hepatorenal syndrome $\cdot$ Hepatic encephalopathy $\cdot$ Liver transplant

\section{Introduction}

Liver cirrhosis is a serious cause of death not only in Japan but also in all developed countries. It is a diffuse hepatic process characterized by fibrosis and structurally abnormal nodules, representing the final histological change for a variety of chronic liver diseases. A decrease in the frequency of hepatitis $\mathrm{C}$ virus (HCV) infection as a major 
cause of cirrhosis and an increase in the number of non-B, non- $\mathrm{C}$ cirrhosis cases have recently been noted in Japan. Cirrhosis is not a single disease entity, but has serious complications, which exacerbate the disease prognosis. With continuous hepatocyte destruction and collagen deposition, the liver is shrunken in size and distorted in shape, forming multiple nodules of liver cells separated by broad fibrotic bands, which disturbs intrahepatic blood circulation and induces portal hypertension with extensive portocarval shunts. The major complications of cirrhosis, such as gastroesophageal varices, ascites, hepatic encephalopathy, and renal and cardiac disturbances, occur mainly as a consequence of portal hypertension and hyperdynamic circulation and their hemodynamic and metabolic effects.

In 2010, the Japanese Society of Gastroenterology developed evidence-based clinical practice guidelines for liver cirrhosis, and these guidelines were revised in 2015. These were world premiere comprehensive guidelines for liver cirrhosis, because the former American or European clinical practice guidelines for cirrhosis were divided into several themes - that is, hepatitis B, hepatitis C, alcoholic liver diseases, portal hypertension, ascites/hepatorenal syndrome (HRS), and hepatic encephalopathy-and not directed at liver cirrhosis as a whole.

A working committee (Chair, H. Fukui; Vice-Chair, H. Saito; Y. Ueno; H. Uto H; I. Sakaida; A. Shibuya; M. Seike; M. Segawa; and S. Nagoshi) and an evaluation committee (Chair, H. Tsubouchi; Vice-Chair, H. Moriwaki; A. Kato; E. Hashimoto; K. Michitaka; and Y. Murawaki) collaborated to create the guidelines. The revised guideline consists of six sections: conception, diagnosis, treatment, complications, prognosis, and liver transplant. The sections on treatment and complications are subdivided into several items as described below. Eighty-three clinical questions (CQs) were selected, and a literature search was performed for the CQs with use of the MEDLINE, Cochrane, and Igaku Chuo Zasshi databases for the period between 1983 and June 2012. In the theme containing marked recent progress or change, each working committee member added manual searching to get the latest literature until August 2015. The guidelines were developed with use of the Grading of Recommendations Assessment, Development, and Evaluation (GRADE) system [1]. The quality of evidence was graded as A (high), B (moderate), C (low), or D (very low). The strength of a recommendation was indicated as either " 1 ", (strong recommendation) or " 2 '" (weak recommendation) [1]. Consensus was previously defined as $70 \%$ or more votes in agreement.

In this article, we summarize the main CQs and statements and our consensuses on the management of liver cirrhosis and its complications.

\section{Diagnosis of liver cirrhosis}

Basic information on the cause of liver cirrhosis, on the characteristics of the patients, and from physical examination first gives a clue to the suspected diagnosis. Liver biopsy has been the gold standard for the diagnosis of liver cirrhosis. However, it is an invasive procedure and has some limitations, including sampling error and interobserver variation. Although several noninvasive diagnostic methods have appeared, the combination of selected methods such as the determination of fibrosis scores based on several blood tests, evaluation of tissue stiffness by transient elastography, and a morphological assessment with other imaging tools or liver biopsy is useful for the diagnosis of liver cirrhosis in practice. A diagnostic algorithms is shown in Fig. 1. An ideal simple noninvasive method should be further sought in the combination of numerous blood markers and imaging modalities.

\section{Nutritional therapy}

\section{CQ: Does a late-evening snack improve the prognosis of cirrhotic patients?}

- Although its effect on prognosis is not clear, it is proposed for cirrhotic patients on the basis of its effect on energy metabolism and quality of life (QOL). (Evidence level C, strength 2)

Comment: A late-evening snack (LES) of $200 \mathrm{kcal}$ such as a rice ball, liquid nutrient, and branched-chain amino acid (BCAA)-enriched supplementation improves nocturnal fasting, improves nutritional status, increasing body protein content [2], and diminishes fat and protein oxidation [3]. It suppresses serum free fatty acid levels [4] and recovers energy metabolism (i.e., respiratory quotient: RQ) [5] at 1 week and serum albumin levels and nitrogen balance at 3 months [6]. Although its effect on survival has not been reported, it improves health-related QOL [7]. Its nutritional effects help cirrhotic patients with refractory ascites undergoing repeated paracentesis [8] and those with hepatocellular carcinoma (HCC) receiving chemoembolization [9].

\section{CQ: Is oral BCAA administration effective for man- agement of liver cirrhosis?}

- It is recommended for cirrhotic patients because it relieves hypoalbuminemia and hepatic encephalopathy and improves QOL. (Evidence level B, strength 2)

Comment: Long-term oral BCAA supplementation improves event-free survival, increases serum albumin levels, and improves QOL in patients with decompensated cirrhosis with hypoalbuminemia (serum albumin level of 


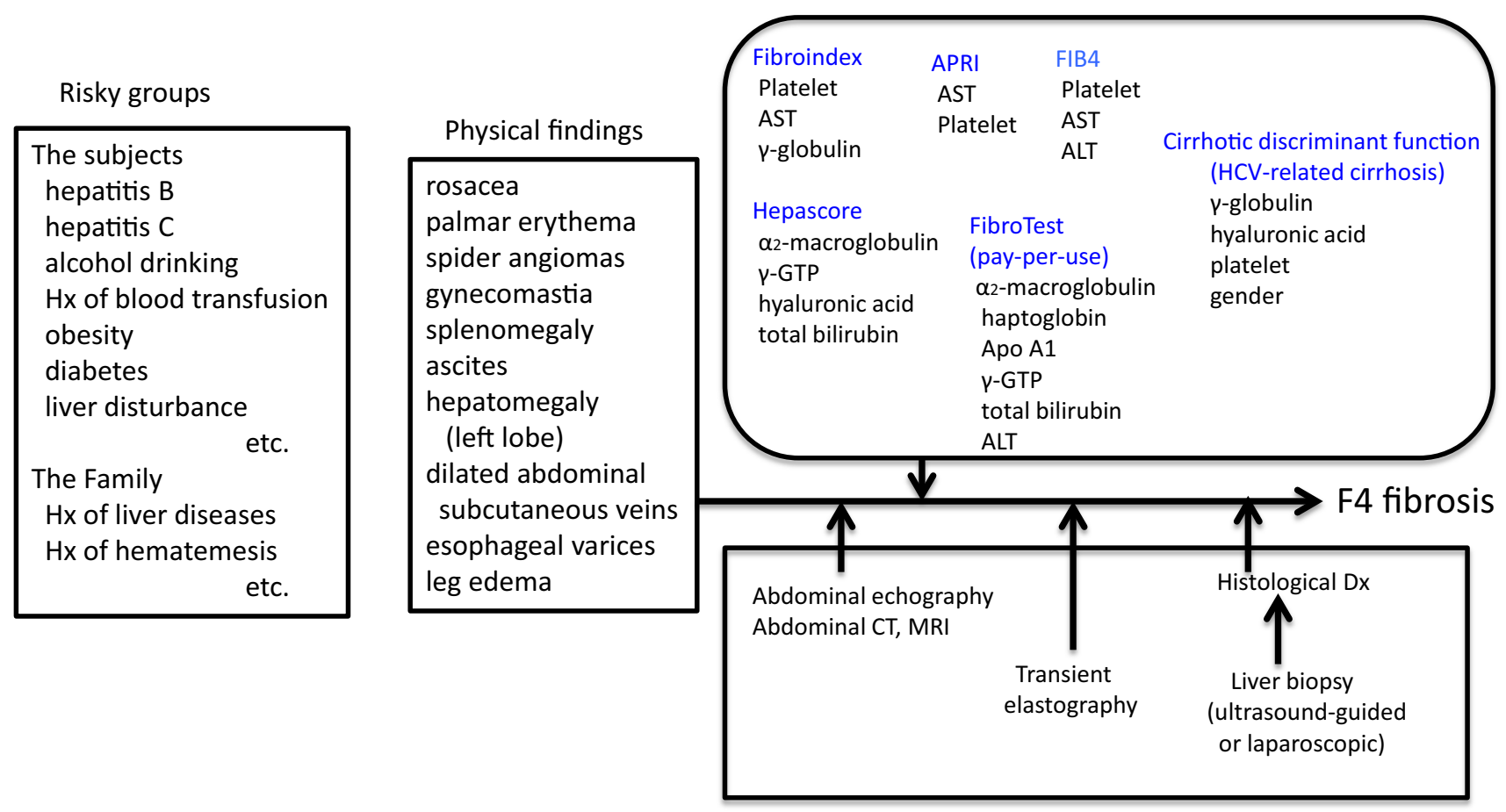

Fig. 1 Diagnostic algorithm for liver cirrhosis. After obtaining basic information on the cause of liver cirrhosis, on the characteristics of the patients, and from physical examination, we should combine several diagnostic tools such as numerous serum biomarkers and imaging modalities as noninvasive alternatives to liver biopsy. This algorithm diagnoses cirrhotic F4 fibrosis. A special blood test or

$3.5 \mathrm{~g} / \mathrm{dL}$ or lower) [10], whereas BCAA granules show no effect on serum albumin levels in patients with compensated cirrhosis (serum albumin level between 3.6 and $4.5 \mathrm{~g} / \mathrm{dL}$ ) [11]. Perioperative supplementation with a BCAA-enriched nutrient mixture reduces the morbidity associated with postoperative complications, preserves serum albumin levels, and shortens the duration of hospitalization of patients undergoing liver resection for HCC [12]. The annual changes in the Model for End-Stage Liver Disease (MELD) score, Child-Pugh score, and asialoscintigraphic clearance index were smaller and the incidence of ascites was lower in cirrhotic patients taking BCAA granules, which suggests that early interventional oral BCAA administration may prolong the liver transplant waiting period [13]. Although oral BCAA supplementation after an episode of hepatic encephalopathy does not decrease recurrence of hepatic encephalopathy, it relieves minimal hepatic encephalopathy and increases muscle mass. [14]. It is also associated with reduced incidence of $\mathrm{HCC}$ in patients with Child-Pugh A cirrhosis [15] and in patients with a BMI of $25 \mathrm{~kg} / \mathrm{m}^{2}$ or higher [16]. histological characteristics are often needed to determine the cause of cirrhosis. ALT alanine aminotransferase, Apo apolipoprotein, APRI aspartate aminotransferase to platelet ratio index, $A S T$ aspartate aminotransferase, $D x$ diagnosis, FIB4 fibrosis $4, H C V$ hepatitis C virus, $H x$ history

Figure 2 shows an algorithm for nutritional therapy in patients with liver cirrhosis.

\section{Antiviral therapy for hepatitis B virus related cirrhosis}

CQ: Do nucleoside analogues enhance sustained virological response (SVR) or hepatitis B e antigen (HBeAg) seroconversion in patients with hepatitis $B$ virus (HBV)-related cirrhosis?

- Nucleoside analogues (lamivudine, adefovir, entecavir, and tenofovir) are recommended for such patients because they enhance SVR and HBeAg seroconversion. (Evidence level A, strength 1)

CQ: Do nucleoside analogues relieve liver fibrosis and improve prognosis? Do they suppress the development of $\mathrm{HCC}$ ?

- Administration of nucleoside analogues is recommended for $\mathrm{HBV}$-related cirrhosis because they relieve liver 


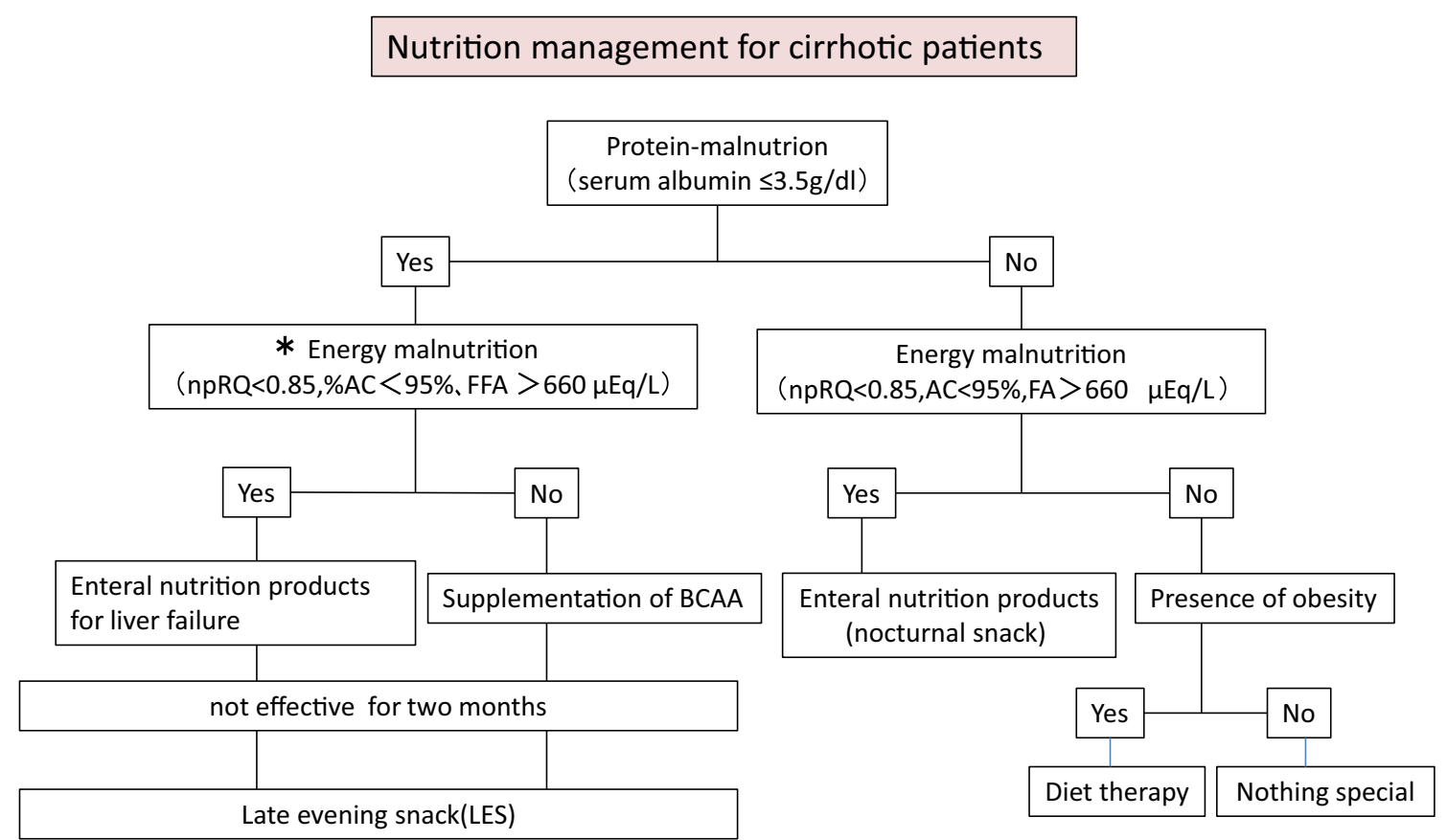

Fig. 2 Algorithm for nutritional therapy in patients with liver cirrhosis. The nonprotein respiratory quotient $(n p R Q)$ measured by indirect calorimetry is considered to be a good marker to estimate energy malnutrition. A decrease in npRQ (less than 0.85) in cirrhotic patients predicts lower survival rate. However, measurement of npRQ is limited in daily clinical practice. Subjective global assessment (SGA), dualenergy X-ray absorptiometry (DEXA), bioelectrical impedance (BIA),

fibrosis and improve patient prognosis and prevent the development of HCC. (Evidence level A, strength 1)

\section{CQ: Are adefovir and tenofovir effective for management of lamivudine-resistant HBV-related liver cirrhosis?}

- Adefovir add-on therapy or a switch to tenofovir therapy is recommended in this case. (Evidence level A, strength 1)

\section{CQ: Does interferon relieve liver fibrosis and suppress the development of $\mathrm{HCC}$ in $\mathrm{HBV}$-related liver cirrhosis?}

- Interferon therapy is not recommended for patients with $\mathrm{HBV}$-related liver cirrhosis because there is not enough evidence of its effects on fibrosis and HCC in liver cirrhosis. (Evidence level C, strength 2)

Comment: Continuous lamivudine (LDV) treatment results in $\mathrm{HBeAg}$ seroconversion and undetectable $\mathrm{HBV}$ DNA levels [17], and delays clinical progression of HBVrelated cirrhosis by reducing hepatic decompensation and HCC development [18]. Administration of adefovir dipivoxil (ADV) for 12.6 months (median) offered a clinical benefit [undetectable HBV DNA $41.2 \%$, alanine aminotransferase (ALT) level normalization $55.2 \%$ ] in cirrhotic handgrip strength (HG), and L3 skeletal muscle index are used to determine nutrition disorders in patients with liver cirrhosis as nutrition assessments alternative to npRQ. Percent arm circumference $(A C)$ and free fatty acid $(F F A)$ level are correlated with npRQ. The cut-off values of percent $\mathrm{AC}$ and FFA level to predict $\mathrm{npRQ}=0.85$ are equivalent to $95 \%$ and $660 \mu \mathrm{Eq} / \mathrm{L}$ respectively by receiver operating characteristic (ROC) analysis. BCAA branched-chain amino acids

patients in whom LDV therapy failed [19]. One-year initial entecavir (ETV) therapy was similarly effective in both patients with compensated cirrhosis and patients with decompensated cirrhosis and it improved underlying liver function in decompensated cirrhotic patients [20]. ALT level normalization and $\mathrm{HBe} A g$ loss/seroconversion were similarly expected with tenofovir disoproxil fumarate (TDF) and ETV in patients with decompensated cirrhosis [21]. TDF and ETV are superior to LDV in reducing HBV DNA levels, normalizing ALT levels, and suppressing the increase of Child-Pugh scores [22]. Viral resistance to long-term ADV therapy and ETV therapy is rarer (ADV $29 \%$ for 5 years [23] and ETV $0 \%$ for 699 days (median) [24]) than that to LDV (49\% for 699 days (median) [18]). A meta-analysis concluded that TDF and ETV are the most potent antiviral agents for $\mathrm{HBeAg}$-positive patients in the first year of treatment, whereas TDF is recommended for $\mathrm{HBeAg-negative}$ patients [25].

Long-term treatment with LDV [26], ETV [27], ADV [23], or TDF [28] was reported to reverse HBV-related cirrhosis to milder fibrosis. ETV was more effective than LDV in reducing fibrosis in advanced hepatic fibrosis or cirrhosis [29]. Long-term LDV or ETV therapy decreased 
Child-Pugh scores and MELD scores [20, 30]. Continuous LDV therapy reduces the risk of $\mathrm{HCC}$ in $\mathrm{HBV}$-related chronic hepatitis and cirrhosis (Ishak fibrosis score 4-6) [18]. The cumulative incidence of HCC was $6.9 \%$ at 24 months in patients with HBV-related decompensated cirrhosis receiving ETV treatment [20].

ADV as add-on therapy to LDV therapy was effective for management of LDV-resistant HBV-related cirrhosis (undetected HBV DNA 41.2-100 \%, ALT level normalization 31-82 \%, 2-point decreased Child-Pugh score 64-92 \%) [19, 31-34]. Virological breakthrough was rarer in the LDV plus ADV therapy group than in the ADV monotherapy group [35]. TDF retains efficacy against highly LDV/ADV-resistant HBV in heavily pretreated patients [36]. Patients with decompensated cirrhosis receiving LDV plus ADV therapy are at risk of early death and HCC development despite the antiviral effects [37]. Renal disturbance (creatinine clearance less than $50 \mathrm{~mL} /$ min) and hypophosphatemia (phosphate level less than $2 \mathrm{mg} / \mathrm{dL}$ ) were very rare (less than $1 \%$ ) in group receiving TDF therapy for 96 weeks [38], whereas the incidences of serum creatinine level elevation and hypophosphatemia (phosphate level less than $2.5 \mathrm{mg} / \mathrm{dL}$ ) in the group receiving LDV plus ADV add-on therapy for 15-68 weeks were 38 and $16 \%$, respectively [39].

No study has ever confirmed the beneficial effect of interferon on liver fibrosis in HBV-related cirrhosis. With regard to an HCC-preventing effect, contradictory results were reported both in randomized controlled trials (RCTs) [40, 41] and in meta-analyses [42, 43]. Serious adverse effects, such as bacterial infections and hepatic failure, should not be ignored in interferon therapy for advanced cirrhosis.

\section{Antiviral therapy for $\mathrm{HCV}$-related cirrhosis}

\section{CQ: Does interferon therapy suppress the development} of HCC and improve the prognosis of patients with HCV-related liver cirrhosis?

- Interferon therapy is proposed for patients with compensated HCV-related cirrhosis because it suppresses HCC development and there is a possibility of an improvement in the prognosis of such patients. (Evidence level B, strength 2)

CQ: Is liver fibrosis relieved when SVR is attained by interferon therapy in $\mathrm{HCV}$-related liver cirrhosis?

- Liver fibrosis is gradually relieved when SVR is attained in HCV-related cirrhosis.
Comment: Although early studies did not show this clearly $[44,45]$, recent studies reported that achieving SVR with interferon plus ribavirin therapy markedly reduces the risk of HCC [46-49] and improves survival [47, 49] in compensated HCV-related cirrhosis. However, long-term peginterferon therapy did not reduce the incidence of HCC among patients who did not achieve SVRs [50].

Second biopsy after peginterferon $\alpha_{2}$ a and peginterferon $-\alpha_{2} b$ therapy revealed a $33-49 \%$ reversal of cirrhosis $[51$, 52]. The incidence of this reversal was $61-68 \%$ in cirrhotic patients with SVR [52, 53]. Decrease of fibrosis scores was noted in patients with SVR or virological relapse with this therapy [54]. Multiple regression analyses proved that SVR is one significant predictive factor for the relief of severe fibrosis and cirrhosis [54].

CQ: Is interferon equally effective for management of chronic hepatitis and cirrhosis type $\mathbf{C}$ ?

- The SVR rate of genotype 1 to peginterferon plus ribavirin therapy is lower in patients with compensated cirrhosis than that in those with chronic hepatitis. The rate of SVR of genotype 2 to the therapy is the same between patients with compensated cirrhosis and patients with chronic hepatitis. Peginterferon plus ribavirin therapy is not recommended for patients with decompensated cirrhosis because of their low adherence and SVR rates and the high incidence of adverse events. (Evidence level A, strength 1)

CQ: Is peginterferon plus ribavirin therapy effective for HCV-related cirrhosis which did not respond to first interferon therapy?

- Peginterferon plus ribavirin therapy is not proposed for cirrhotic patients who did not respond to first interferon therapy because the therapy results in a low SVR rate and has little effect on survival and little beneficial effect with regard to HCC development and disease progression. (Evidence level C, strength 2)

CQ: Does interferon therapy not induce adverse events and worsen the prognosis of patients?

- Although interferon therapy in compensated HCVrelated cirrhosis is more frequently associated with adverse effects and treatment interruption than in chronic hepatitis, careful dose adjustment allows safe and effective therapy. Interferon therapy is thus proposed as a treatment option for patients with compensated HCV-related cirrhosis. Direct-acting antivirals are also proposed if indicated. (Evidence level B, strength 2) 
Comment: The rate of SVR with peginterferon plus ribavirin therapy was reported to range from 10 to $44 \%$ for genotypes 1 and 4 and from 33 to $72 \%$ for genotypes 2 and 3 in compensated cirrhosis [55]. Although HCV clearance by the therapy is associated with a reduced risk of liver decompensation, HCC development, and liver-related death [55], these benefits have to be counterbalanced by the increased risk of side effects, such as severe infections in patients with advanced cirrhosis [56].

Di Marco et al. [57] reported that previous nonresponse to interferon monotherapy did not significantly affect the SVR rate on retreatment with peginterferon alone or peginterferon plus ribavirin therapy. In contrast, Giannini et al. [58] reported that nonresponse to a previous antiviral therapy is an important determinant of reduced response to full-dose therapy with peginterferon and ribavirin in cirrhosis and portal hypertension. Di Bisceglie et al. [59] noted that long-term half-dose peginterferon therapy did not suppress disease progression and HCC development in cirrhotic patients who did not respond to initial peginterferon plus ribavirin therapy and concluded that this therapy is not indicated for these patients.

Peginterferon- $\alpha_{2 \mathrm{a}}$ plus ribavirin therapy is effective and well tolerated in patients with bridging fibrosis or cirrhosis, although a decrease in platelet counts (less than $50 \times 10^{3} /$ $\mu \mathrm{L}$ ) during the treatment was significantly more frequent in these patients than in patients with milder fibrosis [60]. In long-term maintenance therapy, most cirrhotic patients are unable to tolerate prolonged treatment with full doses of peginterferon and ribavirin [61]. However, if an SVR is attained by a carefully scheduled therapy, it has a positive impact on decompensated patients as well, improving overall survival and reducing the risk of further events of hepatic decompensation [62]. An additional long-term, low-dose peginterferon therapy for non-SVR patients was proven to add no clinical benefit and was associated with an excess overall mortality [63, 64]. Although this mortality was primarily due to non-liver-related causes [64], long-term interferon therapy should be avoided. Interferon therapy may soon be replaced by therapy with rapidly progressing direct-acting antivirals (i.e., asunaprevir, daclatasvir, and sofosvir) in patients with liver cirrhosis.

\section{Antifibrotic therapy}

\section{CQ: Is there any antifibrotic therapy for viral cirrhosis except antiviral therapy?}

- No therapy has confirmed efficacy. (Evidence level C.)

Comment: Ursodeoxycholic acid (UDCA) stabilizes serum ALT levels in HCV-related liver cirrhosis [65], and glycyrrhizin injection is useful for the prevention of disease progression [66]. However, their effects on liver fibrosis have not been confirmed. Administration of UDCA for 1 year [67] or angiotensin-blocking agents for 1.5-3.5 years [68] failed to relieve fibrosis in chronic hepatitis and cirrhosis. Colchicine suppressed the serum $\mathrm{N}$-terminal peptide of type III procollagen level in chronic liver diseases, including cirrhosis [69], whereas histological improvement was not observed after 1 year [70], and a meta-analysis failed to reveal its beneficial effects on liverrelated mortality and complications [71]. Phlebotomy was reported to prevent the progression of liver fibrosis of chronic hepatitis C [72].

\section{Therapy for nonviral liver cirrhosis}

CQ: Does abstinence from drinking alcohol suppress the progression of fibrosis and improve the prognosis of patients with alcoholic liver cirrhosis?

- Abstinence is recommended for such patients because long-lasting abstinence improves their prognosis. (Evidence level A, strength 1)

Comment: Despite large-scale prospective studies in 1960-1980, the effect of abstinence from drinking alcohol on alcoholic fibrosis remains to be clarified. Continued heavy drinking was associated with poor survival of cirrhotic patients [73]. The mortality in patients with advanced alcoholic cirrhosis was extremely high (5 years $71 \%$, 15 years $90 \%$ ) [74]. High age and continuous alcohol consumption of more than $10 \mathrm{~g}$ ethanol per day were independent predictors of a poor prognosis [74]. The prognostic importance of abstinence was demonstrated in both Child-Pugh A/B and Child-Pugh C patients [75].

CQ: Does corticosteroid therapy relieve liver fibrosis and improve the prognosis of patients with autoimmune hepatitis and liver cirrhosis?

- Corticosteroid therapy is proposed for patients with active autoimmune-hepatitis-related cirrhosis because relief of fibrosis and improvement of prognosis are expected for responders. (Evidence level A, strength 1.)

- Corticosteroid therapy is not proposed for patients with inactive autoimmune-hepatitis-related cirrhosis because its effect is uncertain. (Evidence level A, strength 1.)

Comment: Fibrosis was relieved in $53 \%$ of patients and progressed in $25 \%$ of patients with long-term corticosteroid therapy [76]. Nodular fibrosis/cirrhosis was relieved in 9 of 14 patients [77]. Cirrhotic change returned to normal by the repeated wedge liver biopsy 14 years later in a female patient [78]. Although cirrhosis was associated with a poorer outlook in some studies [79], the rates of 
remission (78\% vs $76 \%$ ), treatment failure (14\% vs $13 \%)$, and 10-year survival (89\% vs $90 \%$ ) were comparable in patients with and without cirrhosis [80]. As the response is excellent even in those with variceal bleeding or ascites, the treatment should not be withheld in patients with decompensated cirrhosis and active disease [81]. In contrast, corticosteroid therapy is not indicated for patients with inactive cirrhosis, who receive no benefit from the therapy [82].

CQ: Do UDCA and corticosteroid therapy relieve liver fibrosis and improve the prognosis of patients with the cirrhotic stage of primary biliary cirrhosis?

- UDCA therapy is recommended for such patients because it can improve their prognosis. (Evidence level A, strength 1)

- Corticosteroid therapy is not recommended for such patients because it is related to many adverse effects. (Evidence level A, strength 2)

Comment: In contrast to the previous negative data [83, 84], UDCA was reported to delay the progression of liver fibrosis [85, 86] and even relieve fibrosis of cirrhotic patients [87]. Some studies supported its beneficial effect on prognosis [86, 88-90], whereas others, including a Cochrane database systemic review, did not support it [9194]. Good biochemical response to UDCA is related to good prognosis [95] and poor response is related to disease progression [96] and HCC development [97]. Although the histological stage was considered as a major determinant of the therapeutic effect [98], recent logistic regression analysis showed that not the primary biliary cirrhosis stage but esophageal varices and poor UDCA response were related to high mortality risk [90]. As for the use of corticosteroid therapy, the extrahepatic adverse effects such as infection, diabetes, or peptic ulcer are considered to outweigh the slight improvement of liver function in advanced cirrhosis.

CQ: Do UDCA and corticosteroid therapy improve the prognosis of patients with liver cirrhosis due to primary sclerosing cholangitis?

- Corticosteroid therapy does not improve their survival and is not recommended for them. (Evidence level A, strength 1)

- UDCA therapy is proposed as a treatment option for them, although its effect is uncertain. (Evidence level A, strength 2)

Comment: A Cochrane database systemic review reported that corticosteroid therapy tended to increase the incidence of adverse events and resulted in no cholangiographic improvement [99]. An RCT revealed that high-dose UDCA therapy (28-30 mg/kg/day) did not improve survival, although it suppressed serum ALT and alkaline phosphatase levels [100]. The therapy was associated with increased risk of esophagogastric varices and mortality, suggesting a risk of high-dose UDCA therapy for patients with primary sclerosing cholangitis [100]. On the basis of variable data on its effects on liver tests and survival [100-103], UDCA therapy is not recommended in the American Association for the Study of Liver Diseases (AASLD) [104] and European Association for the Study of the Liver (EASL) [105] guidelines. We propose its careful use as a treatment option after assessment of the benefit-risk balance.

\section{Gastrointestinal bleeding and portal hypertension}

CQ: Which is more useful endoscopic variceal ligation (EVL) or endoscopic injection sclerotherapy (EIS) in preventing recurrence of esophageal varices?

- EIS is recommended for preventing recurrence because both the recurrence and the bleeding rates after EIS are lower than the corresponding rates after EVL. (Evidence level A, strength 1)

Comment: Although the eradication rate of esophageal varices was not significantly different between the two groups, the rate of recurrence of esophageal varices was higher in the EVL group than in the EIS group [106]. Gotoh et al. [107] concluded that EVL was ineffective as a prophylactic therapy, because both recurrence of and bleeding from oesophageal varices during a 18-month follow-up period were observed more frequently in the EVL group than in the EIS group (recurrence $56 \%$ vs $16 \%$, bleeding $20 \%$ vs $0 \%$ ). EVL was proved to be no more effective than no treatment in preventing initial variceal bleeding [108]. Repeated EIS was preferable to combined therapy with EVL as a means of preventing the recurrence of esophageal varices [109].

CQ: Are $\beta$-blockers useful in preventing bleeding from esophageal varices?

- $\beta$-Blockers are useful for primary prophylaxis of esophageal variceal bleeding. The combination of endoscopic therapy and $\beta$-blockers is proposed for secondary prophylaxis of esophageal variceal bleeding as it decreases rebleeding and mortality. (Evidence level A, strength 2)

CQ: Is combined therapy with a $\beta$-blocker and isosorbide 5-mononitrate (ISMN) useful in preventing bleeding from esophageal varices?

- Combined therapy with a $\beta$-blocker and ISMN is proposed for the prevention of variceal bleeding 
because it is effective in suppressing both the initial and recurrent bleeding from esophageal varices. (Evidence level A, strength 2)

\section{CQ: Are $\beta$-blockers effective for management of portal hypertensive gastropathy?}

- Propranolol is proposed for management of portal hypertensive gastropathy because it is effective in relieving portal hypertensive gastropathy. (Evidence level A, strength 2)

Comment: Several RCTs proved that nonselective $\beta$ blockers are effective in preventing initial [110] or recurrent [111] hemorrhage from esophageal varices. Several RCTs have reported that $\beta$-blockers were as effective as EVL in preventing initial variceal bleeding $[112,113]$ or as effective as EIS in preventing recurrent variceal bleeding [114], whereas other RCTs have reported that EVL was more effective than propranolol for the primary prevention of high-risk variceal bleeding [115, 116]. Pérez-Ayuso et al. [117] concluded in their RCT that propranolol should be considered the first choice for primary prophylaxis in the case of variceal bleeding, offering similar effects as and fewer severe adverse events than EVL. Funakoshi et al. [118] summarized their meta-analysis as indicating that current evidence is insufficient to recommend EVL over $\beta$ blockers as first-line therapy. They further found that the combination of a $\beta$-blocker and endoscopic treatment significantly reduced rebleeding and mortality compared with endoscopic treatment alone.

Villanueva et al. $[119,120]$ reported that combined therapy with nadolol and ISMN was more effective than EIS or EVL alone for the prevention of recurrent variceal bleeding, but Lo et al. [121] reported that EVL was more effective than the combination of nadolol and ISMN. Wang et al. [122] reported that the combination of nadolol plus ISMN was similar to EVL with regard to effectiveness and safety in the prevention of initial variceal bleeding. Another RCT reported that the rebleeding rate of esophageal varices over 6 months was $38 \%$ in the propranolol group, $31 \%$ in the EVL group, $26 \%$ in the proplanorol plus ISMN group, and $22 \%$ in the EVL plus proplanorol plus ISMN group. In a meta-analysis, the rebleeding rate was not significantly different between the $\beta$-blocker plus ISMN group and the EVLalone group, but the combination treatment exhibited a survival advantage over EVL alone when all-cause mortality was evaluated [123]. They concluded that a $\beta$-blocker plus ISMN was the best choice for the prevention of rebleeding [123].

Propranolol, in addition to lowering portal pressure, reduces gastric blood perfusion in cirrhotic patients with portal hypertensive gastropathy, which may contribute to prevention of bleeding from these lesions [124]. Long-term propranolol treatment (12 and 30 months) was proven to reduce the frequency of rebleeding from severe portal hypertensive gastropathy [125]. Multivariate analysis showed that the absence of propranolol treatment was the only predictive variable for rebleeding [125]. The occurrence of portal hypertensive gastropathy after EVL for treatment of esophageal varices was significantly reduced by propranolol therapy [126].

\section{CQ: Are vasoactive agents effective for management of esophageal variceal bleeding?}

- Vasoactive agents (vasopressin, terlipressin, somatostatin, or octreotide) are effective in controlling esophageal variceal bleeding. The administration of these agents is proposed after EVL. (Evidence level A, strength 2)

Comment: In a meta-analysis, the use of vasoactive agents (vasopressin, somatostatin, and their analogues terlipressin, vapreotide, and octreotide) was associated with a significantly lower risk of acute all-cause death and transfusion requirements, and improved control of bleeding and shortened hospital stay [127]. Studies comparing various vasoactive medications showed no significant differences in efficacy among them [127]. D'Amico et al. [128] reviewed 17 RCTs comparing emergency sclerotherapy with vasopressin (with or without nitroglycerin), terlipressin, somatostatin, or octreotide in their meta-analysis and reported that sclerotherapy did not appear to be superior to the vasoactive drugs in terms of control of initial bleeding, number of transfusions, 42-day rebleeding, or mortality. However, emergency EVL plus octreotide therapy is superior to octreotide therapy alone at a lower cost while combining higher efficacy with a sufficient degree of safety [129].

\section{CQ: Is injection of cyanoacrylate effective for man- agement of gastric varices $(\mathrm{GV})$ ?}

- Injection of cyanoacrylate is recommended for the management of bleeding GV because it is more effective than $\beta$-blocker medication or EVL alone. (Evidence level A, strength 1)

Comment: Endoscopic obliteration using cyanoacrylate is more effective and facilitates the obliteration of GV faster than EIS with alcohol [130]. Endoscopic obturation using cyanoacrylate proved more effective and safer with a lower rebleeding rate than EVL in the management of $\mathrm{GV}$ bleeding [131, 132]. It is also more effective than $\beta$-blocker medication for the prevention of initial and recurrent GV rebleeding and improving survival [133, 134], and it has proven to be highly effective in the management of fundal GV bleeding [135]. 
CQ: Is balloon-occluded retrograde transvenous obliteration (B-RTO) effective for management of GV?

- B-RTO is proposed as an elective therapy after hemostasis of initial GV bleeding using cyanoacrylate and as a prophylactic therapy in the management of high-risk GV. (Evidence level C, strength 2.)

Comment: Kanagawa et al. [136] inserted a balloon catheter into an outflow shunt (gastrorenal or gastric-inferior vena cava) via the femoral or internal jugular vein. After blocking the blood flow by inflating the balloon, they injected $5 \%$ ethanolamine oleate iopamidol in a retrograde manner and embolized the GV. They concluded that B-RTO was a safe and effective procedure for the treatment of fundal $\mathrm{GV}$, as eradication of the varices was confirmed in 31 of 32 patients without serious side effects [136]. Hong et al. [137] reported that EIS with cyanoacrylate was associated with a higher rebleeding rate than B-RTO, although the immediate efficacies of these two treatments for bleeding GV and high-risk GV were similar. Akahoshi et al. [138] reported that B-RTO was superior to EIS with cyanoacrylate and ethanolamine oleate in preventing rebleeding from isolated fundal $\mathrm{GV}$ with a major shunt. The 8-year cumulative bleeding rates for bleeding GV and nonbleeding high-risk GV after B-RTO were $14 \%$ and $0 \%$ respectively [139]. The cumulative occurrence rate for high-risk esophageal varices was $22 \%$, and no patients died of variceal bleeding [139]. These results led to a consensus in Japan that B-RTO can serve as a first-choice radical treatment after hemostasis for $\mathrm{GV}$ bleeding and prophylactic treatment for high-risk GV.

\section{Ascites}

The proper management of ascites begins with an optimal testing strategy for differential diagnosis. Diagnostic paracentesis should include cell count, differential cell count, and measurement of total protein and albumin concentration to rule out asymptomatic spontaneous bacterial peritonitis (SBP). Bacterial culture is also necessary if ascitic fluid infection is suspected. Figure 3 shows the diagnostic algorithm for cirrhotic ascites.

\section{CQ: Is a salt-restricted diet effective for treatment of cirrhotic patients with ascites?}

- A salt-restricted diet is considered effective for mild to moderate ascites. A mild salt-restricted diet to maintain appetite is proposed for such patients. (Evidence level C, strength 2)

Comment: Although dietary salt has been restricted in European countries, this may cause protein malnutrition [140]. Contradictory results have been presented on the effect of salt restriction on the disappearance of ascites in patients taking diuretics [141, 142]. The importance of an evening protein snack was stressed over salt restriction in survival of cirrhotic patients with refractory ascites [8]. In

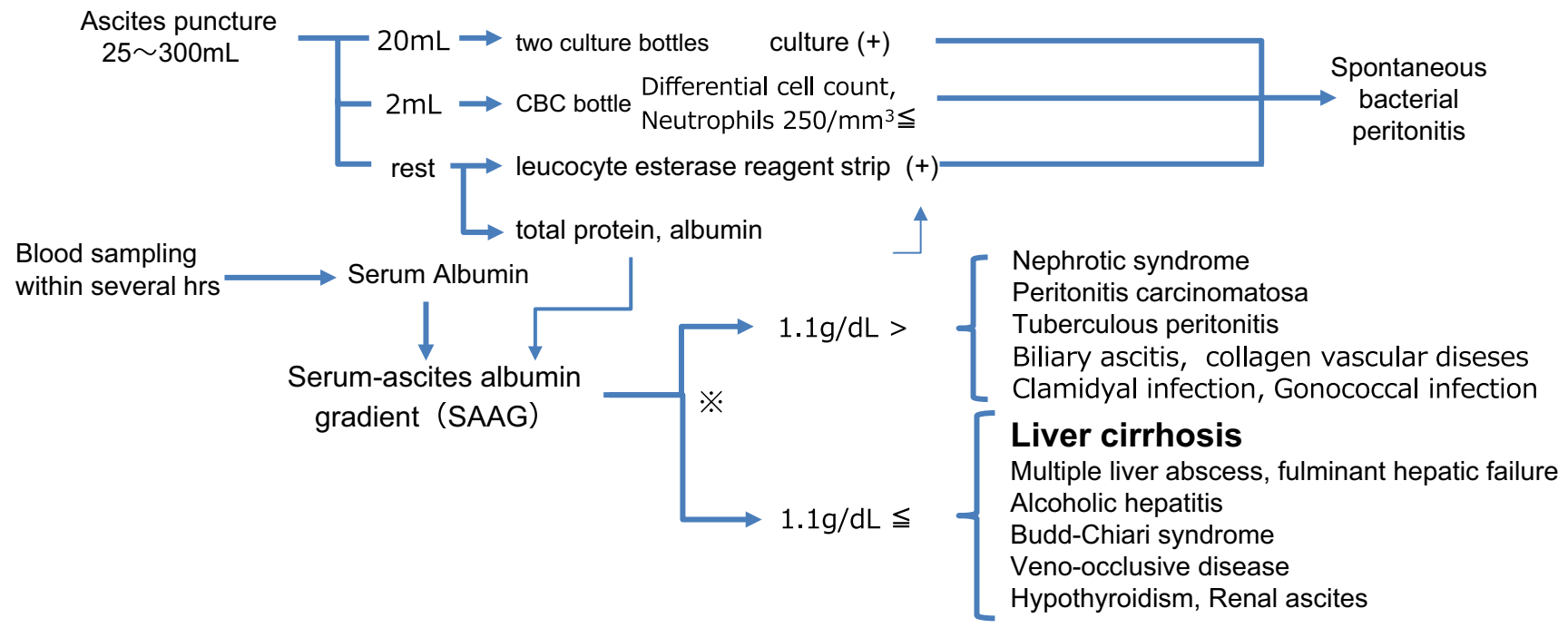

Fig. 3 Diagnostic algorithm for cirrhotic ascites. Ascitic fluid obtained by diagnostic paracentesis should be examined for total protein, albumin, and LDH levels, cell count, and differential cell count. If necessary, Gram and acid-fast staining and culture are performed. If the serum-ascites albumin gradient $(S A A G)$ is greater than or equal to $1.1 \mathrm{~g} / \mathrm{dL}$, the patient is considered to have portal hypertension. If the SAAG is less than $1.1 \mathrm{~g} / \mathrm{dL}$, portal hypertension can be excluded. Although the SAAG is useful for the diagnosis of cirrhotic ascites, we need to determine the cause of ascites as a whole, because there are exceptions. A diagnosis of spontaneous bacterial peritonitis $(S B P)$ is made when there is a positive ascitic fluid bacterial culture and an elevated ascitic fluid absolute polymorphonuclear leukocyte count (i.e., at least 250 cells per microliter) without an evident intra-abdominal, surgically treatable source of infection. $※$ Of note, SAAG is less than $1.1 \mathrm{~g} / \mathrm{dl}$ in patients with SBP. $C B C$ complete blood cell count 
Japan, mild salt restriction ( $85-120 \mathrm{mmol} / \mathrm{day})$ may be proposed to avoid appetite loss.

\section{CQ: Is albumin infusion effective for treatment of cir- rhotic patients with ascites?}

- It is effective. Albumin infusion is proposed for such patients because it increases the effect of diuretics and prevents paracentesis-induced circulatory disturbance. It also relieves circulatory disturbances and prevents the development of HRS. (Evidence level A, strength 2)

Comment: Albumin binds and transports loop diuretics to the proximal convoluted tubule in the kidney. Albumin infusion improves the response of diuretics and shortens the hospital stay of ascitic patients [143]. A meta-analysis showed that it reduces morbidity (incidence of paracentesis-induced circulatory disturbance and hyponatremia) and mortality of patients with tense ascites undergoing largevolume paracentesis (LVP) as compared with alternative treatments (saline or other plasma expanders) [144]. SBP is a most important precipitating event for the development of type 1 HRS characterized by rapid progressive renal failure with poor prognosis [145]. An RCT proved the preventive effect of albumin infusion on the development of type 1 HRS in patients with SBP receiving antibiotics [146].

CQ: Are loop diuretics more effective than the aldosterone antagonist spironolactone for treatment of cirrhotic patients with ascites?

- No. Spironolactone is recommended as a single drug. (Evidence level A, strength 1)

CQ: Is spironolactone alone or in combination with loop diuretics better for treatment of cirrhotic patients with ascites?

- Although outpatients can be first treated with spironolactone alone, the combination therapy is rather proposed for inpatients receiving intensive therapy to prevent side effects. (Evidence level C, strength 2)

Comment: Controlled studies showed that spironolactone achieves better natriuresis and diuresis than a loop diuretic such as furosemide [140]. In European countries, first-line treatment of ascites is with spironolactone, increasing from 100 to $400 \mathrm{mg} /$ day [140]. If this fails, furosemide is added at a dosage of up to $160 \mathrm{mg} /$ day [140]. However, this sequential therapy more frequently led to adverse effects (in particular, hyperkalemia) than the combined diuretic treatment [147]. The EASL guidelines recommend the combination therapy as a step-up regimen for recurrent ascites [148]. The usual diuretic regimen recommended by the AASLD guidelines consists of single morning doses of orally administered spironolactone $(100 \mathrm{mg})$ and furosemide $(40 \mathrm{mg})$ [149].
CQ: Are vasopressin $V_{2}$ receptor antagonists effective for management of ascites or water retention in cirrhotic patients?

- A vasopressin $\mathrm{V}_{2}$ receptor antagonist combined with loop diuretics and aldosterone antagonists is recommended for such patients on the basis of its effectiveness on hyponatremia and ascites. (Evidence level A, strength 1)

Comment: Given the central role of vasopressin in limiting renal water excretion in cirrhotic patients, use of vasopressin $\mathrm{V}_{2}$ receptor antagonists is a rational approach for ascetic patients. Among them, tolvaptan $(7.5-30 \mathrm{mg} / \mathrm{day}$ for 7 days) showed add-on effects to conventional diuretics on ascites in multicenter RCTs for poor responders to the standard diuretic therapy (furosemide at $40 \mathrm{mg}$ /day or greater and spironolactone at $25 \mathrm{mg} /$ day or greater; or furosemide at $20 \mathrm{mg}$ /day or greater and spironolactone at $50 \mathrm{mg} /$ day or greater) $[150,151]$. As a dosage of $7.5 \mathrm{mg} /$ day showed the maximum effects with preferable tolerability [151] and a dosage of $3.75 \mathrm{mg} /$ day also exerted significant effects [152], the proper dosage was determined as $3.75-7.5 \mathrm{mg} /$ day. The effects were unrelated to serum albumin levels [150]. Minor increases in serum creatinine levels defined as acute kidney injury by the International Club of Ascites adversely affect survival of cirrhotic patients $[153,154]$. To avoid acute kidney injury and electrolyte disturbances caused by high-dose diuretics, we propose the combined use of tolvaptan and diuretics for ascitic patients (Fig. 4).

CQ: Is large volume paracenthesis (LVP) useful for patients with refractory ascites?

- Yes. Paracentesis with albumin infusion is recommended for such patients as the first-line therapy. (Evidence level A, strength 1)

CQ: Is cell-free and concentrated ascites reinfusion therapy (CART) useful for patients with refractory ascites?

- It is useful just like paracentesis with albumin infusion and is proposed for such patients. (Evidence level B, strength 2)

Comment: Paracentesis with albumin infusion is a fast, effective, and safe therapy for ascites in cirrhosis [155]. It achieves a marked reduction of intra-abdominal, intrathoracic, and pulmonary pressures [156] and a rapid fall of portal pressure [157] without any renal and hepatic dysfunction [155]. LVP is considered as the first-line therapy for tense ascites in the EASL guidelines [148] and AASLD guidelines [149]. Although plasma expanders and saline could replace albumin when less than $5 \mathrm{~L}$ of ascitic 
Small moderate amount of ascites spironolactone $25 \sim 100 \mathrm{mg}$

+ furosemide $20 \sim 80 \mathrm{mg}$ p.o.

resistant

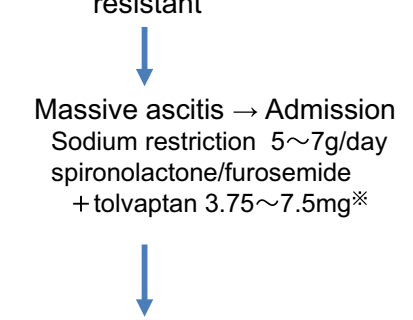

pottasium canrenoate $200 \sim 600 \mathrm{mg}$

+ furosemide $20 \sim 100 \mathrm{mg}$ i.v.

(beginning with $20 \mathrm{mg}$,

be increased, if necessary)

albumin infusion diuretic-resistant or diuretic-intractable ascites

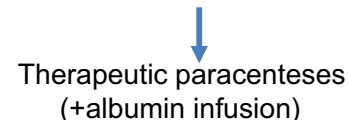

(+albumin infusion)

cell-free and concentrated ascites reinfusion therapy (CART)

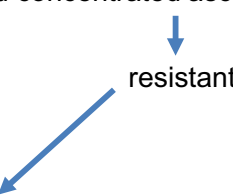

peritoneovenous shunt

(PVS)

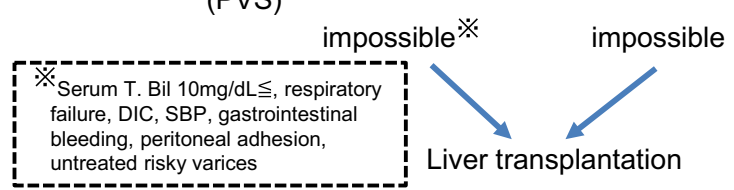

$<70$ years of age

Child-Pugh score $\leqq 11$

transjugular intrahepatic portosystemic stent-shunt

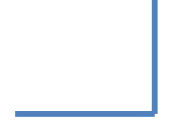
(TIPS)

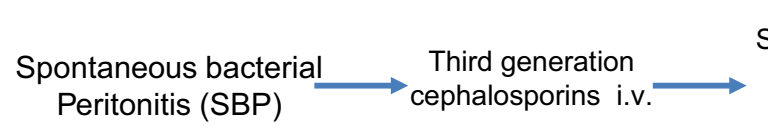

Serum $\mathrm{Cr} 1.0 \mathrm{mg} / \mathrm{dL} \leqq$ BUN $30 \mathrm{mg} / \mathrm{dL} \leqq$ or + Albmin infusion (1.5g/kg b.w.)

T. Bil $4.0 \mathrm{mg} / \mathrm{dL} \leqq$

Fig. 4 Therapeutic algorithm for cirrhotic ascites. The first-choice diuretic for a small to moderate amount of ascites is spironolactone $(25-100 \mathrm{mg} / \mathrm{day})$. If it is not effective, furosemide $(20-80 \mathrm{mg} /$ day orally) is added. Patients with massive or nonresponsive ascites should be admitted. Under sodium restriction (5-7 g/day), either an add-on therapy with the $\mathrm{V}_{2}$ receptor antagonist tolvaptan (3.75-7.5 mg/day orally) or an intravenous infusion of potassium canrenoate/furosemide is recommended. For those with severe hypoalbuminemia (albumin level below $2.5 \mathrm{~g} / \mathrm{dL}$ ), albumin infusion (20-25\% albumin at $50 \mathrm{~mL} /$ day, up to 6 times per month) can be considered. (strictly controlled by the public medical insurance systems in Japan). We should be careful of the underfilling state of patients to prevent adverse effects of diuretics. For patients resistant to these medications, therapeutic paracentesis or cell-free and concentrated ascites reinfusion therapy is indicated. Albumin infusion

fluid is evacuated in Europe [158, 159], we should be more cautious about LVP for small Asian patients to prevent a risky underfilling state which may lead to hepatic encephalopathy or renal failure. The prognosis of patients does not improve with the procedure [160]. The reinfusion of concentrated ascitic fluid by means of CART is safe and effective just like LVP with albumin infusion [161], although the costs of the instruments and staff and the allergic reactions may be considered as drawbacks [162]. In Japan its benefit to reduce albumin use is emphasized.

\section{CQ: Is peritoneovenous shunt (PVS) useful for treat- ment of patients with refractory ascites?}

- Despite many serious complications and no survival advantage compared with diuretic therapy, it can relieve symptoms and shorten the hospital stay. It may be proposed for patients when other treatments are impossible. (Evidence level A, strength 2) after large-volume paracentesis has been proved to be useful for the prevention of paracentesis-induced circulatory disturbance, although this is restricted in the public medical insurance systems in Japan. Patients with spontaneous bacterial peritonitis $(S B P)$ should receive empiric antibiotic therapy, (e.g., an intravenously administered thirdgeneration cephalosporin). The American Association for the Study of Liver Diseases guidelines recommended an add-on albumin infusion when the serum creatinine $(\mathrm{Cr})$ level is greater than $1 \mathrm{mg} /$ $\mathrm{dL}$, the blood urea nitrogen $(B U N)$ level is greater than $30 \mathrm{mg} / \mathrm{dL}$, or the total bilirubin (T.Bil.) level is greater than $4 \mathrm{mg} / \mathrm{dL}$ for the prevention of hepatorenal syndrome. (This therapy is not approved by the public medical insurance systems in Japan). b.w. body weight, DIC disseminated intravascular coagulation, i.v. intravenously, p.o. per os

CQ: Is transjugular intrahepatic portosystemic stentshunt (TIPS) useful for treatment of patients with refractory ascites?

- Compared with LVP with albumin infusion, TIPS is more effective in controlling ascites, preventing its recurrence, and improving mental QOL and survival. Although it frequently causes hepatic encephalopathy and needs technical skills, it can be proposed for appropriately selected patients. (Evidence level A, strength 2)

Comment: PVS was specifically designed to palliate ascites by reintroducing ascitic fluid into the systemic circulation (LeVeen or Denver shunt). PVS was reported to increase the glomerular filtration rate and provide palliation in $83 \%$ of patients with intractable ascites waiting for liver transplant [163]. Control of ascites was achieved sooner after PVS than after TIPS, but long-term efficacy favored TIPS [164]. PVS significantly prolonged the time to the 
recurrence of ascites compared with diuretic treatment [165] and LVP with albumin infusion [166]. However, the poor long-term patency, excessive complications (disseminated intravascular coagulation, cardiac failure, sepsis, etc.), and no survival advantage compared with medical therapy in controlled trials have restricted the use of PVS to when other treatments are impossible [149]. Several metaanalyses based on RCTs revealed that TIPS is superior in controlling ascites than LVP, although it causes hepatic encephalopathy more frequently [167-170]. The use of narrow-diameter dilation by TIPS decreased the incidence of severe hepatic encephalopathy [171]. The introduction of a covered stent offers better symptomatic control and overall survival, especially in patients with a MELD score of less than 16 at the baseline [172, 173].

Although previous meta-analyses [167, 169, 170, 174] concluded that TIPS does not improve survival compared with LVP, recent meta-analyses [145, 173] involving newer RCTs reported that TIPS significantly improves transplant-free survival. Improvement in mental QOL assessed by the mental component score of SF-36 was associated with TIPS [175].

A therapeutic algorithm for cirrhotic ascites is shown in Fig. 4.

CQ: Are prophylactic antibiotics for cirrhotic patients with gastrointestinal (GI) bleeding or severe liver disease useful in preventing SBP or improving survival?

- They are useful. Prophylactic use of antibiotics is proposed for cirrhotic patients with GI bleeding because it significantly suppresses the development of SBP, bacterial infection, and sepsis and significantly reduces infection mortality and overall mortality. (Evidence level A, strength 2)

- It is also proposed as an optional treatment for those with an ascites protein concentration lower than $1.5 \mathrm{~g} /$ $\mathrm{dL}$ and advanced liver failure because it significantly suppresses the development of SBP and severe infection and significantly reduces mortality. (Evidence level A, strength 2)

CQ: Are prophylactic antibiotics for cirrhotic patients with an episode of SBP useful in preventing the recurrence of SBP or improving survival?

- Prophylactic use of antibiotics is proposed for such patients because it is useful in preventing the recurrence of SBP. (Evidence level A, strength 2)

Comment: The mortality rates of cirrhotic patients with SBP at 1 and 12 months were reported to be $32.5 \%$ and $66.2 \%$, respectively [176]. A meta-analysis of 1241 cirrhotic patients with upper GI bleeding revealed that prophylactic use of antibiotics significantly suppressed not only the development of SBP but also bacterial infection and sepsis and significantly reduced infection mortality and overall mortality [177]. Recurrence of upper GI bleeding was further proved to be suppressed by the therapy [178]. Norfloxacin prophylaxis reduced the incidence of SBP, delayed the development of HRS, and improved survival in cirrhotic patients with low ascites protein levels (less than $1.5 \mathrm{~g} / \mathrm{dL}$ ) and advanced liver failure (Child-Pugh score of 9 points or greater with a serum bilirubin level of $3 \mathrm{mg} / \mathrm{dL}$ or greater) or impaired renal function [179]. Fluoroquinolone prophylaxis also reduced the risk of the development of a first episode of SBP and mortality in cirrhotic patients with low ascites protein levels [180].

\section{Hepatorenal syndrome}

CQ: Is terlipressin with albumin infusion effective for treatment of cirrhotic patients with HRS?

- Terlipressin with albumin infusion is proposed for patients with type 1 HRS because $46 \%$ of them improve with this therapy. (Evidence level A, strength 2)

CQ: Are sympathomimetic drugs or octreotide effective for treatment of cirrhotic patients with HRS?

- Combination treatment with octreotide, midodrine, and albumin infusion improves the survival of patients with type 1 and type 2 HRS. Norepinephrine infusion and albumin infusion is proposed for patients with HRS because they are as effective as octreotide, midodrine, and albumin infusion. (Evidence level C, strength 2)

Comment: Two types of HRS have been described. Type 1 is a rapidly progressive acute renal failure defined by a doubling of the initial serum creatinine level to greater than $2.5 \mathrm{mg} / \mathrm{dL}$ in less than 2 weeks [181]. It often develops after a precipitating event, particularly SBP. Type 2 HRS is characterized by moderate renal failure (initial serum creatinine level increase from 1.5 to $2.5 \mathrm{mg} / \mathrm{dl}$ ) in patients with refractory ascites, showing a steady or slowly progressive course [181]. Several metaanalyses concluded that terlipressin showed higher efficacy in reversing renal function than placebo in type 1 HRS patients receiving albumin infusion [182-184]. Two of them also reported survival improvement with terlipressin therapy [183, 184]. A case-control study revealed that the regimen of octreotide, midodrine, and albumin significantly improved short-term survival and renal function in both type 1 and type 2 HRS [185]. In addition, RCTs showed that norepinephrine is as safe and 
effective as terlipressin, but is less expensive in the treatment of type 1 and type 2 HRS [186-188]. Norepinephrine and albumin are proposed because norepinephrine is the only drug approved by the National Health Insurance in Japan.

The International Club of Ascites recently proposed a revised consensus recommendation where an increase in initial serum creatinine level greater than twofold from the baseline without a response to withdrawal of diuretics and volume expansion with albumin $(1 \mathrm{~g} / \mathrm{kg})$ for 2 days is considered as type 1 HRS [154]. This revision was in the expectation of a better therapeutic effect by early diagnosis.

\section{CQ: Is PVS effective for management of HRS?}

- PVS is not recommended in patients with HRS because it has no survival benefit. (Evidence level A, strength 1)

\section{CQ: Is TIPS effective for management of HRS?}

- Improvement of renal function, relief of ascites, and improvement of prognosis are expected by TIPS in appropriately selected patients. (Evidence level C)

\section{CQ: Does liver transplant improve the prognosis of patients with HRS?}

- Yes. Liver transplant is recommended for both type 1 and type $2 \mathrm{HRS}$ if indicated. (Evidence level B, strength 1)

Comment: PVS occasionally improves renal function in patients with HRS, but does not prolong survival and has a high risk of severe complications [189]. It has currently very little role in the management of refractory ascites and is not recommended for patients with HRS [148, 190]. Several noncontrolled studies suggest the effects of TIPS on HRS. It improved renal function in type 1 HRS $[191,192]$ and provided probable survival benefits in most of the nontransplantable cases [192]. TIPS further improved renal function and sodium excretion in type 1 HRS patients who responded to combination therapy of midodrine, octreotide, and albumin, leading to normalization of renal function at 12 months [193]. It was concluded that TIPS is an effective treatment for type 1 HRS in suitable patients. A cohort study concluded that liver transplant offered a clear survival benefit to type 1 HRS patients regardless of the therapy they received [194]. More than $50 \%$ of type 1 HRS patients die within 1 month without liver transplant, and the median survival time of patients with type 2 HRS is approximately 6 months [195]. In contrast, patient survival rates after liver transplant at 1 and 5 year were $77 \%$ and $69 \%$, respectively, in type $1 \mathrm{HRS}$ and $74 \%$ and $61 \%$, respectively, in type 2 HRS.

\section{Hepatic encephalopathy}

CQ: Do protein-restricted diets improve the prognosis of cirrhotic patients with hepatic encephalopathy?

- Protein-restricted diets are not proposed for long-term management of cirrhotic patients because they may enhance protein breakdown and worsen the prognosis of cirrhotic patients. (Evidence level C, strength 2)

Comment: A low-protein diet was proved to cause higher protein breakdown compared with diets with a normal protein content. The latter is metabolically more adequate and tolerable for cirrhotic patients with episodic hepatic encephalopathy [196]. Restriction of the protein content in the diet does not confer any benefit to patients during an episode of encephalopathy [197].

CQ: Are disaccharides effective for management of hepatic encephalopathy?

- Disaccharides are recommended for patients with hepatic encephalopathy because they improve the parameters and relieve the symptoms of hepatic encephalopathy. (Evidence level A, strength 1)

Comment: RCTs showed nonabsorbable disaccharides such as lactulose improve the parameters of hepatic encephalopathy (psychometric test scores and venous ammonia levels) [198, 199]. Nonabsorbable disaccharides seemed to reduce the risk of no improvement in patients with hepatic encephalopathy but they showed no significant effect on mortality compared with placebo or no intervention [200]. Lactulose appears to have the most beneficial effect on minimal hepatic encephalopathy, followed closely by probiotics and synbiotics [201].

\section{CQ: Do nonabsorbable antibiotics relieve hepatic encephalopathy?}

- Nonabsorbable antibiotics are proposed for patients with hepatic encephalopathy because they improve the parameters and relieve symptoms of hepatic encephalopathy. (Evidence level A, strength 2)

Comment: Over a 6-month period, treatment with rifaximin maintained remission from hepatic encephalopathy more effectively than did placebo [202]. Driving simulator performance improves significantly in patients with minimal hepatic encephalopathy after treatment with rifaximin compared with placebo [203]. A meta-analysis revealed that rifaximin appears to be at least as effective as disaccharides or other oral antibiotics for the treatment of hepatic encephalopathy, with a better safety profile [204]. Sharma et al. [205] demonstarated by their RCT that the combination of lactulose plus rifaximin is more 
effective (i.e., higher recovery from hepatic encephalopathy and lower mortality) than lactulose alone in the treatment of overt hepatic encephalopathy. Another recent meta-analysis further showed that rifaximin had a beneficial effect on secondary prevention of hepatic encephalopathy, increased the proportion of patients who recovered from hepatic encephalopathy, and reduced mortality [206].

CQ: Is a BCAA-enriched amino acid solution effective in management of overt hepatic encephalopathy?

- It is recommended for management of overt hepatic encephalopathy because it is effective for management of disturbance of consciousness due to hepatic encephalopathy, including coma. (Evidence level A, strength 1)

CQ: Are a BCAA enriched oral mixture and BCAA granules effective for treatment of patients with hepatic encephalopathy?

- Long-term oral BCAA supplementation is recommended for such patients because it relives hepatic encephalopathy and improves the nutritional state. (Evidence level A, strength 1)

Comment: A meta-analysis of seven RCTs showed an improvement in mental state caused by an BCAA-enriched amino acid solution, and the European Society for Clinical Nutrition and Metabolism (ESPEN) guidelines on parental nutrition recommended this solution for grade III to grade IV hepatic encephalopathy [207]. In contrast, another meta-analysis could not present convincing evidence for the benefit of this solution in patients with hepatic encephalopathy because of the low methodological reliability of the old RCTs [208].

Long-term oral BCAA supplementation raises plasma albumin levels and improves QOL [209]. It prevents progressive hepatic failure, improves surrogate markers, improves perceived health status [210], and improves event-free survival in patients with decompensated cirrhosis with an adequate daily food intake [10]. It relieves minimal hepatic encephalopathy, improves neuropsychological test scores, and increases the muscle mass [14]. It may inhibit hepatic carcinogenesis in patients with compensated cirrhosis with a serum albumin level of less than $4.0 \mathrm{~g} / \mathrm{dL}$ [11]. A recent meta-analysis [211] involving eight trials of orally administered BCAA supplements and seven trials of intravenously administered BCAAs concluded that BCAAs had a beneficial effect on hepatic encephalopathy, although we need additional randomized clinical trials to determine the effect of BCAAs compared with interventions such as nonabsorbable disaccharides, rifaximin, or other antibiotics.
CQ: Is B-RTO effective for management of hepatic encephalopathy?

- It is proposed for adequately evaluated and selected patients with portosystemic hepatic encephalopathy because it is effective for these patients. (Evidence level C, strength 2)

Comment: Several noncontrolled case series reported that the occlusion of the large portosystemic shunt by B-RTO relieves hepatic encephalopathy [212-215]. B-RTO is also reported to augment portal venous blood flow and improve liver function test findings [214, 215]. An elevated hepatic venous pressure gradient after B-RTO is one aspect of the effect of liver function [215]. Careful evaluation of portal hemodynamics is necessary to select patients for the efficacy and safety of B-RTO.

\section{Portal vein thrombosis}

CQ: Are anticoagulants useful for treatment of cirrhotic patients with portal vein thrombosis (PVT)?

- Yes. Anticoagulation therapy is proposed for patients with acute-onset or progressive PVT and for candidates for liver transplant. (Evidence level C, strength 2)

Comment: The prevalence of PVT in cirrhotic patients on evaluation or at liver transplant ranges from 5 to $26 \%$ [216]. Survival after liver transplant was worse in recipients with complete PVT [217]. Moreover, the mortality was related to its extension (5.9\% for partial PVT vs $17.5 \%$ for complete PVT) [218]. Partial or complete recanalization after anticoagulation mostly by low molecular weight heparins was achieved in $60 \%$ of patients, where early initiation of anticoagulation was the only factor associated with recanalization [219]. Rethrombosis after complete recanalization occurred in $38.5 \%$ of patients after the stopping of anticoagulation [219]. Benefits of continuous anticoagulation are expected in patients awaiting liver transplant with a MELD score greater than 15 and PVT with extension to the superior mesenteric vein [220].

\section{Splenectomy and partial splenic embolization}

CQ: Are splenectomy and partial splenic embolization (PSE) effective in relieving pathological states of cirrhosis such as ascites, hypoalbuminemia, hepatic encephalopathy, and esophagogastric varices?

- Although splenectomy and PSE occasionally relieve these states, we should be aware of procedural complications. (Evidence level C) 
Comment: Although PSE and splenectomy increase platelet and leukocyte counts, PSE allows preservation of adequate splenic tissue to safeguard against overwhelming infection [221]. Beneficial effects of PSE on refractory ascites after liver transplant were reported [222, 223]. PSE reduced prothrombin time and increased serum albumin levels at 12 months [224]. PSE also lowered the hepatic encephalopathy grade and serum ammonia levels in cirrhotic patients after B-RTO [225]. Although splenectomy reduced the indocyanine green retention rate and increased the technetium-99m-labeled galactosyl human serum albumin value (markers of hepatic functional reserve), it had no effect on serum albumin levels [226]. Laparoscopic splenectomy with EVL was superior to TIPS in the prevention of gastroesophageal variceal rebleeding in cirrhotic patients in a controlled study [227]. PSE combined with EVL was reported to be effective for the control of esophageal varices and hypersplenism, reducing the flow rate and velocity of the main portal vein [228]. Portal thrombosis, ascites, and sepsis are common major complications for PSE and splenectomy.

\section{Liver transplant}

\section{CQ: Does liver transplant increase the survival of patients with decompensated cirrhosis?}

- Although liver transplant increases survival rates, its indication should be carefully evaluated in each patient. (Evidence level B, strength 2)

Comment: There is no study to answer this question directly. Merion et al. [229] analyzed 12,966 patients on the waiting list for liver tranplant and reported that significant and progressively increasing survival benefit was demonstrated in candidates with a MELD score of 18-20. The same group further extended the analysis to 38,899 patients and reported that a survival benefit from liver transplant is seen for candidates with a MELD score of 12 or greater, whereas there is no survival benefit from liver transplant for those with a MELD score of 9-11 and there is even harm to those with a MELD score of 6-8 [230]. A significant survival benefit of living donor liver transplant was observed in Japanese patients with a MELD score of 15 or greater [231].

\section{CQ: Are antiviral therapies useful for management of recurrent HBV and HCV hepatitis after liver transplant?}

- Antiviral therapies are recommended for viral cirrhosis patients receiving a liver transplant because they are useful for management of recurrent $\mathrm{HBV}$ and $\mathrm{HCV}$ hepatitis. (Evidence level A, strength 1)

Comment: Before the introduction of antiviral therapy for liver transplant, $67 \%$ of patients had hepatitis B recurrence at 3 years, and their survival rate was $68 \%$ at 1 year and $44 \%$ at 3 years [232]. After liver transplant for HCV cirrhosis, 20-40\% of patients progressed to allograft cirrhosis within 5 years [233]. The rate of their decompensation was more than $40 \%$ at 1 year and more than $60 \%$ at 3 years [233]. Although nucleoside analogues are useful for preventing hepatitis B recurrence, the recurrence rate was lowest in patients who received combined hepatitis $B$ immunoglobulin plus nucleoside analogue prophylaxis $(6.6 \%)$ compared with those receiving nucleoside analogue prophylaxis alone $(19.0 \%)$ or hepatitis B immunoglobulin prophylaxis alone $(26.2 \%)$ [234]. The combination of hepatitis B immunoglobulin and ADV was more effective than hepatitis B immunoglobulin plus LDV prophylaxis [234].

In recurrent hepatitis $\mathrm{C}$, antiviral therapy slows disease progression (particularly in sustained virological responders) [235]. Peginterferon- $\alpha_{2 b}$ plus ribavirin therapy for 48 weeks led to SVR in $48 \%$ of F0-F2 fibrosis patients and $18.5 \%$ of F3-F4 fibrosis patients [235]. Fibrosis progression by one or more stages was noted in $26 \%$ of treated F0-F2 fibrosis patients, $54 \%$ of treated F3-F4 fibrosis patients and $70 \%$ of untreated F0-F2 fibrosis patients [235].

Acknowledgments This article was supported by a Grant-in-Aid from the Japanese Society of Gastroenterology. The authors thank the investigators and supporters for participating in the studies. The authors express special appreciation to Dr. Akihiko Oshige, Dr. Kouhei Oda, and Dr. Seiichi Mawatari (Kagoshima University).

Conflict of interest All financial relationships with enterprises, businesses or academic institutions in the subject matter or materials discussed in the manuscript are listed as follows; (1) those from which the authors, the spouse, partner or immediate relatives of authors, have received individually any income, honoraria or any other types of remuneration; Ajinomoto Pharmaceuticals Co., Ltd., MSD K.K., Otsuka Pharmaceutical Co., Ltd., Mitsubishi Tanabe Pharma Corporation, Chugai Pharmaceutical Co., Ltd., Bristol-Myers Squibb, Janssen Pharmaceutical K.K. and (2) those from which the academic institutions of the authors received support (commercial/academic cooperation); Ajinomoto Pharmaceuticals Co., Ltd., ASKA Pharmaceutical Co., Ltd., Astellas Pharma Inc., AstraZeneca K. K., Eisai Co., Ltd., SRL Inc., MSD K.K., Otsuka Pharmaceutical Co., Ltd., Kaneka Corporation, KAN Research Institute, Inc., Daiichi Sankyo Company, Limited, Sumitomo Dainippon Pharma Co., Ltd., Takeda Pharmaceutical Company Limited., Mitsubishi Tanabe Pharma Corporation, Chugai Pharmaceutical Co., Ltd., Bristol-Myers Squibb, Minophagen Pharmaceutical Co., Ltd., Rohto Pharmaceutical Co., Ltd.

\section{Appendix}

The members of the Guidelines Committee who created and evaluated the Japanese Society of Gastroenterology "Evidence-based clinical practice guidelines for liver cirrhosis", are listed below. 


\section{Creating Committee}

Chair: Hiroshi Fukui (Nara Medical University)

Vice-Chair: Hidetsugu Saito (Department of Gastroenterology, Keio University)

Members: Yoshiyuki Ueno (Department of Gastroenterology, Yamagata University Faculty of Medicine), Hirofumi Uto (Center for Digestive and Liver Diseases, Miyazaki Medical Center Hospital), Katsutoshi Obara (Department of Advanced Gastrointestinal Endoscopy, Fukushima Medical University), Isao Sakaida (Department of Gastroenterology and Hepatology, Yamaguchi University Graduate School of Medicine), Akitaka Shibuya (Department of Gastroenterology, Kitasato University School of Medicine), Masataka Seike (Central Clinical Facilities/Liver Disease Consultation Unit, Oita University Hospital), Sumiko Nagoshi (Department of Gastroenterology and Hepatology, Saitama Medical Center, Saitama Medical University), and Makoto Segawa (Department of Gastroenterology and Hepatology, Yamaguchi University School of Medicine)

\section{Evaluation Committee}

Chair: Hirohito Tsubouchi (Kagoshima City Hospital) Vice-Chair: Hisataka Moriwaki (Gifu University) Members: Akinobu Kato (Morioka Municipal Hospital), Etsuko Hashimoto (Institute of Gastroenterology, Tokyo Women's Medical University), Kojiro Michitaka (Gastroenterology Center, Ehime Prefectural Central Hospita), and Yoshikazu Murawaki (Tottori Saiseikai Sakaiminato General Hospital)

\section{The Japanese Society of Gastroenterology}

President: Tooru Shimosegawa (Division of Gastroenterology, Tohoku University Graduate School of Medicine)

\section{References}

1. Yoshida M, Kinoshita Y, Watanabe M, et al. JSGE clinical practice guidelines 2014: standards, methods, and process of developing the guidelines. J Gastroenterol. 2015;50:4-10.

2. Plank LD, Gane EJ, Peng S, et al. Nocturnal nutritional supplementation improves total body protein status of patients with liver cirrhosis: a randomized 12-month trial. Hepatology. 2008;48:557-66.

3. Chang WK, Chao YC, Tang HS, et al. Effects of extra-carbohydrate supplementation in the late evening on energy expenditure and substrate oxidation in patients with liver cirrhosis. JPEN J Parenter Enteral Nutr. 1997;21:96-9.

4. Yamauchi M, Takeda K, Sakamoto K, et al. Effect of oral branched chain amino acid supplementation in the late evening on the nutritional state of patients with liver cirrhosis. Hepatol Res. 2001;21:199-204.

5. Yamanaka-Okumura H, Nakamura T, Takeuchi H, et al. Effect of late evening snack with rice ball on energy metabolism in liver cirrhosis. Eur J Clin Nutr. 2006;60:1067-72.

6. Nakaya Y, Okita K, Suzuki K, et al. BCAA-enriched snack improves nutritional state of cirrhosis. Nutrition. 2007;23:113-20.

7. Yamanaka-Okumura H, Nakamura T, Miyake H, et al. Effect of long-term late-evening snack on health-related quality of life in cirrhotic patients. Hepatol Res. 2010;40:470-6.

8. Sorrentino P, Castaldo G, Tarantino L, et al. Preservation of nutritional-status in patients with refractory ascites due to hepatic cirrhosis who are undergoing repeated paracentesis. J Gastroenterol Hepatol. 2012;27:813-22.

9. Takeshita S, Ichikawa T, Nakao K, et al. A snack enriched with oral branched-chain amino acids prevents a fall in albumin in patients with liver cirrhosis undergoing chemoembolization for hepatocellular carcinoma. Nutr Res. 2009;29:89-93.

10. Muto Y, Sato S, Watanabe A, et al. Effects of oral branchedchain amino acid granules on event-free survival in patients with liver cirrhosis. Clin Gastroenterol Hepatol. 2005;3:705-13.

11. Kobayashi M, Ikeda K, Arase Y, et al. Inhibitory effect of branched-chain amino acid granules on progression of compensated liver cirrhosis due to hepatitis $\mathrm{C}$ virus. J Gastroenterol. 2008;43:63-70.

12. Okabayashi T, Nishimori I, Sugimoto T, et al. Effects of branched-chain amino acids-enriched nutrient support for patients undergoing liver resection for hepatocellular carcinoma. J Gastroenterol Hepatol. 2008;23:1869-73.

13. Kawamura E, Habu D, Morikawa $\mathrm{H}$, et al. A randomized pilot trial of oral branched-chain amino acids in early cirrhosis: validation using prognostic markers for pre-liver transplant status. Liver Transpl. 2009;15:790-7.

14. Les I, Doval E, Garcia-Martinez R, et al. Effects of branchedchain amino acids supplementation in patients with cirrhosis and a previous episode of hepatic encephalopathy: a randomized study. Am J Gastroenterol. 2011;106:1081-8.

15. Hayaishi S, Chung H, Kudo M, et al. Oral branched-chain amino acid granules reduce the incidence of hepatocellular carcinoma and improve event-free survival in patients with liver cirrhosis. Dig Dis. 2011;29:326-32.

16. Muto Y, Sato S, Watanabe A, et al. Overweight and obesity increase the risk for liver cancer in patients with liver cirrhosis and long-term oral supplementation with branched-chain amino acid granules inhibits liver carcinogenesis in heavier patients with liver cirrhosis. Hepatol Res. 2006;35:204-14.

17. Lai CL, Chien RN, Leung NW, et al. A one-year trial of lamivudine for chronic hepatitis B. N Engl J Med. 1998;339:61-8.

18. Liaw YF, Sung JJ, Chow WC, et al. Lamivudine for patients with chronic hepatitis B and advanced liver disease. N Engl J Med. 2004;351:1521-31.

19. Zoulim F, Parvaz P, Marcellin P, et al. Adefovir dipivoxil is effective for the treatment of cirrhotic patients with lamivudine failure. Liver Int. 2009;29:420-6.

20. Shim JH, Lee HC, Kim KM, et al. Efficacy of entecavir in treatment-naive patients with hepatitis B virus-related decompensated cirrhosis. J Hepatol. 2010;52:176-82.

21. Liaw YF, Sheen IS, Lee CM, et al. Tenofovir disoproxil fumarate (TDF), emtricitabine/TDF, and entecavir in patients with decompensated chronic hepatitis B liver disease. Hepatology. 2011;53:62-72.

22. Köklü S, Tuna Y, Gulsen MT, et al. Long-term efficacy and safety of lamivudine, entecavir, and tenofovir for treatment of hepatitis B virus-related cirrhosis. Clin Gastroenterol Hepatol. 2013;11:88-94. 
23. Hadziyannis SJ, Tassopoulos NC, Heathcote EJ, et al. Longterm therapy with adefovir dipivoxil for $\mathrm{HBeAg}$-negative chronic hepatitis B for up to 5 years. Gastroenterology. 2006;131:1743-51.

24. Hyun JJ, Seo YS, Yoon E, et al. Comparison of the efficacies of lamivudine versus entecavir in patients with hepatitis B virusrelated decompensated cirrhosis. Liver Int. 2012;32:656-64.

25. Woo G, Tomlinson G, Nishikawa Y, et al. Tenofovir and entecavir are the most effective antiviral agents for chronic hepatitis B: a systematic review and Bayesian meta-analyses. Gastroenterology. 2010;139:1218-29.

26. Dienstag JL, Goldin RD, Heathcote EJ, et al. Histological outcome during long-term lamivudine therapy. Gastroenterology. 2003;124:105-17.

27. Chang TT, Liaw YF, Wu SS, et al. Long-term entecavir therapy results in the reversal of fibrosis/cirrhosis and continued histological improvement in patients with chronic hepatitis B. Hepatology. 2010;52:886-93.

28. Marcellin P, Gane E, Buti M, et al. Regression of cirrhosis during treatment with tenofovir disoproxil fumarate for chronic hepatitis B: a 5-year open-label follow-up study. Lancet. 2013;381:468-75.

29. Schiff E, Simsek H, Lee WM, et al. Efficacy and safety of entecavir in patients with chronic hepatitis B and advanced hepatic fibrosis or cirrhosis. Am J Gastroenterol. 2008;103:2776-83.

30. Yao FY, Terrault NA, Freise C, et al. Lamivudine treatment is beneficial in patients with severely decompensated cirrhosis and actively replicating hepatitis B infection awaiting liver transplantation: a comparative study using a matched, untreated cohort. Hepatology. 2001;34:411-6.

31. Schiff ER, Lai CL, Hadziyannis S, et al. Adefovir dipivoxil therapy for lamivudine-resistant hepatitis B in pre- and postliver transplantation patients. Hepatology. 2003;38:1419-27.

32. Perrillo R, Hann HW, Mutimer D, et al. Adefovir dipivoxil added to ongoing lamivudine in chronic hepatitis $B$ with YMDD mutant hepatitis B virus. Gastroenterology. 2004;126:81-90.

33. Kim KM, Choi WB, Lim YS, et al. Adefovir dipivoxil alone or in combination with ongoing lamivudine in patients with decompensated liver disease and lamivudine-resistant hepatitis B virus. J Korean Med Sci. 2005;20:821-8.

34. Liaw YF, Lee CM, Chien RN, Yeh CT. Switching to adefovir monotherapy after emergence of lamivudine-resistant mutations in patients with liver cirrhosis. J Viral Hepat. 2006;13:250-5.

35. Vassiliadis TG, Giouleme O, Koumerkeridis G, et al. Adefovir plus lamivudine are more effective than adefovir alone in lamivudine-resistant $\mathrm{HBeAg}$ - chronic hepatitis B patients: a 4-year study. J Gastroenterol Hepatol. 2010;25:54-60.

36. Patterson SJ, George J, Strasser SI, et al. Tenofovir disoproxil fumarate rescue therapy following failure of both lamivudine and adefovir dipivoxil in chronic hepatitis B. Gut. 2011;60:247-54.

37. Lim SG, Aung MO, Mak B, et al. Clinical outcomes of lamivudine-adefovir therapy in chronic hepatitis B cirrhosis. J Clin Gastroenterol. 2011;45:818-23.

38. Fung S, Kwan P, Fabri M, et al. Randomized comparison of tenofovir disoproxil fumarate vs emtricitabine and tenofovir disoproxil fumarate in patients with lamivudine-resistant chronic hepatitis B. Gastroenterology. 2014;146:980-8.

39. Tamori A, Enomoto M, Kobayashi S, et al. Add-on combination therapy with adefovir dipivoxil induces renal impairment in patients with lamivudine-refractory hepatitis B virus. J Viral Hepat. 2010;17:123-9.

40. Ikeda K, Saitoh S, Suzuki Y, et al. Interferon decreases hepatocellular carcinogenesis in patients with cirrhosis caused by the hepatitis B virus: a pilot study. Cancer. 1998;82:827-35.
41. International Interferon- $\alpha$ Hepatocellular Carcinoma Study Group. Effect of interferon- $\alpha$ on progression of cirrhosis to hepatocellular carcinoma: a retrospective cohort study. Lancet 1998;351:1535-9.

42. Yang YF, Zhao $\mathrm{W}$, Zhong YD, et al. Interferon therapy in chronic hepatitis $\mathrm{B}$ reduces progression to cirrhosis and hepatocellular carcinoma: a meta-analysis. J Viral Hepat. 2009;16:265-71.

43. Camma C, Giunta M, Andreone P, Craxi A. Interferon and prevention of hepatocellular carcinoma in viral cirrhosis: an evidence-based approach. J Hepatol. 2001;34:593-602.

44. Valla DC, Chevallier M, Marcellin P, et al. Treatment of hepatitis $\mathrm{C}$ virus-related cirrhosis: a randomized, controlled trial of interferon alfa- $2 \mathrm{~b}$ versus no treatment. Hepatology. 1999;29:1870-5.

45. Testino G, Ansaldi F, Andorno E, et al. Interferon therapy does not prevent hepatocellular carcinoma in $\mathrm{HCV}$ compensated cirrhosis. Hepatogastroenterology. 2002;49:1636-8.

46. Hung CH, Lee CM, Lu SN, et al. Long-term effect of interferon alpha-2b plus ribavirin therapy on incidence of hepatocellular carcinoma in patients with hepatitis $\mathrm{C}$ virus-related cirrhosis. J Viral Hepat. 2006;13:409-14.

47. Bruno S, Stroffolini T, Colombo M, et al. Sustained virological response to interferon- $\alpha$ is associated with improved outcome in HCV-related cirrhosis: a retrospective study. Hepatology. 2007;45:579-87.

48. Floreani A, Baldo V, Rizzotto ER, et al. Pegylated interferon alpha-2b plus ribavirin for naive patients with HCV-related cirrhosis. J Clin Gastroenterol. 2008;42:734-7.

49. Velosa J, Serejo F, Marinho R, et al. Eradication of hepatitis C virus reduces the risk of hepatocellular carcinoma in patients with compensated cirrhosis. Dig Dis Sci. 2011;56:1853-61.

50. Lok AS, Everhart JE, Wright EC, et al. Maintenance peginterferon therapy and other factors associated with hepatocellular carcinoma in patients with advanced hepatitis C. Gastroenterology 2011;140:840-9.e1; quiz e12.

51. Poynard T, McHutchison J, Manns M, et al. Impact of pegylated interferon alfa- $2 \mathrm{~b}$ and ribavirin on liver fibrosis in patients with chronic hepatitis C. Gastroenterology. 2002;122:1303-13.

52. Camma C, Di Bona D, Schepis F, et al. Effect of peginterferon alfa-2a on liver histology in chronic hepatitis $\mathrm{C}$ : a meta-analysis of individual patient data. Hepatology. 2004;39:333-42.

53. D'Ambrosio R, Aghemo A, Fraquelli M, et al. The diagnostic accuracy of Fibroscan for cirrhosis is influenced by liver morphometry in HCV patients with a sustained virological response. J Hepatol. 2013;59:251-6.

54. Everson GT, Balart L, Lee SS, et al. Histological benefits of virological response to peginterferon alfa-2a monotherapy in patients with hepatitis $\mathrm{C}$ and advanced fibrosis or compensated cirrhosis. Aliment Pharmacol Ther. 2008;27:542-51.

55. Vezali E, Aghemo A, Colombo M. A review of the treatment of chronic hepatitis $\mathrm{C}$ virus infection in cirrhosis. Clin Ther. 2010;32:2117-38.

56. Iacobellis A, Siciliano M, Annicchiarico BE, et al. Sustained virological responses following standard anti-viral therapy in decompensated HCV-infected cirrhotic patients. Aliment Pharmacol Ther. 2009;30:146-53.

57. Di Marco V, Almasio PL, Ferraro D, et al. Peg-interferon alone or combined with ribavirin in $\mathrm{HCV}$ cirrhosis with portal hypertension: a randomized controlled trial. J Hepatol. 2007;47:484-91.

58. Giannini EG, Basso M, Savarino V, Picciotto A. Predictive value of on-treatment response during full-dose antiviral therapy of patients with hepatitis $\mathrm{C}$ virus cirrhosis and portal hypertension. J Intern Med. 2009;266:537-46. 
59. Di Bisceglie AM, Shiffman ML, Everson GT, et al. Prolonged therapy of advanced chronic hepatitis $\mathrm{C}$ with low-dose peginterferon. N Engl J Med. 2008;359:2429-41.

60. Bruno S, Shiffman ML, Roberts SK, et al. Efficacy and safety of peginterferon alfa-2a (40KD) plus ribavirin in hepatitis $\mathrm{C}$ patients with advanced fibrosis and cirrhosis. Hepatology. 2010;51:388-97.

61. Shiffman ML, Di Bisceglie AM, Lindsay KL, et al. Peginterferon alfa-2a and ribavirin in patients with chronic hepatitis $\mathrm{C}$ who have failed prior treatment. Gastroenterology 2004;126:1015-23; discussion 947.

62. Iacobellis A, Perri F, Valvano MR, et al. Long-term outcome after antiviral therapy of patients with hepatitis $\mathrm{C}$ virus infection and decompensated cirrhosis. Clin Gastroenterol Hepatol. 2011;9:249-53.

63. Shiffman ML, Morishima C, Dienstag JL, et al. Effect of HCV RNA suppression during peginterferon alfa-2a maintenance therapy on clinical outcomes in the HALT-C trial. Gastroenterology. 2009;137:1986-94.

64. Di Bisceglie AM, Stoddard AM, Dienstag JL, et al. Excess mortality in patients with advanced chronic hepatitis $\mathrm{C}$ treated with long-term peginterferon. Hepatology. 2011;53:1100-8.

65. Lirussi F, Beccarello A, Bortolato L, et al. Long-term treatment of chronic hepatitis $\mathrm{C}$ with ursodeoxycholic acid: influence of $\mathrm{HCV}$ genotypes and severity of liver disease. Liver. 1999;19:381-8.

66. Ikeda K, Kawamura Y, Kobayashi M, et al. Prevention of disease progression with anti-inflammatory therapy in patients with HCV-related cirrhosis: a Markov model. Oncology. 2014;86:295-302.

67. Bellentani S, Podda M, Tiribelli C, et al. Ursodiol in the longterm treatment of chronic hepatitis: a double-blind multicenter clinical trial. J Hepatol. 1993;19:459-64.

68. Abu Dayyeh BK, Yang M, Dienstag JL, Chung RT. The effects of angiotensin blocking agents on the progression of liver fibrosis in the HALT-C Trial cohort. Dig Dis Sci. 2011;56:564-8.

69. Muntoni S, Rojkind M, Muntoni S. Colchicine reduces procollagen III and increases pseudocholinesterase in chronic liver disease. World J Gastroenterol. 2010;16:2889-94.

70. Nikolaidis N, Kountouras J, Giouleme O, et al. Colchicine treatment of liver fibrosis. Hepatogastroenterology. 2006;53:281-5.

71. Rambaldi A, Gluud C. Colchicine for alcoholic and non-alcoholic liver fibrosis or cirrhosis. Liver. 2001;21:129-36.

72. Yano M, Hayashi H, Wakusawa S, et al. Long term effects of phlebotomy on biochemical and histological parameters of chronic hepatitis C. Am J Gastroenterol. 2002;97:133-7.

73. Borowsky SA, Strome S, Lott E. Continued heavy drinking and survival in alcoholic cirrhotics. Gastroenterology. 1981;80:1405-9.

74. Bell H, Jahnsen J, Kittang E, et al. Long-term prognosis of patients with alcoholic liver cirrhosis: a 15-year follow-up study of 100 Norwegian patients admitted to one unit. Scand J Gastroenterol. 2004;39:858-63.

75. Pessione F, Ramond MJ, Peters L, et al. Five-year survival predictive factors in patients with excessive alcohol intake and cirrhosis. Effect of alcoholic hepatitis, smoking and abstinence. Liver Int. 2003;23:45-53.

76. Czaja AJ, Carpenter HA. Progressive fibrosis during corticosteroid therapy of autoimmune hepatitis. Hepatology. 2004;39:1631-8.

77. Schvarcz R, Glaumann H, Weiland O. Survival and histological resolution of fibrosis in patients with autoimmune chronic active hepatitis. J Hepatol. 1993;18:15-23.

78. Cotler SJ, Jakate S, Jensen DM. Resolution of cirrhosis in autoimmune hepatitis with corticosteroid therapy. J Clin Gastroenterol. 2001;32:428-30.
79. Gleeson D, Heneghan MA. British Society of Gastroenterology (BSG) guidelines for management of autoimmune hepatitis. Gut 2011;60:1611-29.

80. Roberts SK, Therneau TM, Czaja AJ. Prognosis of histological cirrhosis in type 1 autoimmune hepatitis. Gastroenterology. 1996;110:848-57.

81. Ishibashi H, Komori A, Shimoda S, Gershwin ME. Guidelines for therapy of autoimmune liver disease. Semin Liver Dis. 2007;27:214-26.

82. Manns MP, Czaja AJ, Gorham JD, et al. Diagnosis and management of autoimmune hepatitis. Hepatology. 2010;51:2193-213.

83. Matsuzaki Y, Doy M, Tanaka N, et al. Biochemical and histological changes after more than four years of treatment of ursodeoxycholic acid in primary biliary cirrhosis. J Clin Gastroenterol. 1994;18:36-41.

84. Degott C, Zafrani ES, Callard P, et al. Histopathological study of primary biliary cirrhosis and the effect of ursodeoxycholic acid treatment on histology progression. Hepatology. 1999;29:1007-12.

85. Corpechot C, Carrat F, Bonnand AM, et al. The effect of ursodeoxycholic acid therapy on liver fibrosis progression in primary biliary cirrhosis. Hepatology. 2000;32:1196-9.

86. Shi J, Wu C, Lin Y, et al. Long-term effects of mid-dose ursodeoxycholic acid in primary biliary cirrhosis: a meta-analysis of randomized controlled trials. Am J Gastroenterol. 2006;101:1529-38.

87. Neuman MG, Cameron RG, Haber JA, et al. An electron microscopic and morphometric study of ursodeoxycholic effect in primary biliary cirrhosis. Liver. 2002;22:235-44.

88. Bateson MC, Gedling P. Ursodeoxycholic acid therapy for primary biliary cirrhosis. A 10 -year British single-centre population-based audit of efficacy and survival. Postgrad Med J. 1998;74:482-5.

89. Corpechot C, Carrat F, Bahr A, et al. The effect of ursodeoxycholic acid therapy on the natural course of primary biliary cirrhosis. Gastroenterology. 2005;128:297-303.

90. Floreani A, Caroli D, Variola A, et al. A 35-year follow-up of a large cohort of patients with primary biliary cirrhosis seen at a single centre. Liver Int. 2011;31:361-8.

91. Pares A, Caballeria L, Rodes J, et al. Long-term effects of ursodeoxycholic acid in primary biliary cirrhosis: results of a double-blind controlled multicentric trial. J Hepatol. 2000;32:561-6.

92. Chan CW, Gunsar F, Feudjo M, et al. Long-term ursodeoxycholic acid therapy for primary biliary cirrhosis: a follow-up to 12 years. Aliment Pharmacol Ther. 2005;21:217-26.

93. Papatheodoridis GV, Hadziyannis ES, Deutsch M, et al. Ursodeoxycholic acid for primary biliary cirrhosis: final results of a 12-year, prospective, randomized, controlled trial. Am J Gastroenterol. 2002;97:2063-70.

94. Rudic JS, Poropat G, Krstic MN, et al. Ursodeoxycholic acid for primary biliary cirrhosis. Cochrane Database Syst Rev 2012;(12):CD000551.

95. Kuiper EM, Hansen BE, de Vries RA, et al. Improved prognosis of patients with primary biliary cirrhosis that have a biochemical response to ursodeoxycholic acid. Gastroenterology. 2009;136:1281-7.

96. Kumagi T, Guindi M, Fischer SE, et al. Baseline ductopenia and treatment response predict long-term histological progression in primary biliary cirrhosis. Am J Gastroenterol. 2010;105:2186-94.

97. Kuiper EM, Hansen BE, Adang RP, et al. Relatively high risk for hepatocellular carcinoma in patients with primary biliary cirrhosis not responding to ursodeoxycholic acid. Eur J Gastroenterol Hepatol. 2010;22:1495-502.

98. Poupon RE, Lindor KD, Pares A, et al. Combined analysis of the effect of treatment with ursodeoxycholic acid on histologic 
progression in primary biliary cirrhosis. J Hepatol. 2003;39:12-6.

99. Giljaca V, Poropat G, Stimac D, Gluud C. Glucocorticosteroids for primary sclerosing cholangitis. Cochrane Database Syst Rev. 2010. doi:10.1002/14651858.

100. Lindor KD, Kowdley KV, Luketic VA, et al. High-dose ursodeoxycholic acid for the treatment of primary sclerosing cholangitis. Hepatology. 2009;50:808-14.

101. Mitchell SA, Bansi DS, Hunt N, et al. A preliminary trial of high-dose ursodeoxycholic acid in primary sclerosing cholangitis. Gastroenterology. 2001;121:900-7.

102. Harnois DM, Angulo P, Jorgensen RA, et al. High-dose ursodeoxycholic acid as a therapy for patients with primary sclerosing cholangitis. Am J Gastroenterol. 2001;96:1558-62.

103. Olsson R, Boberg KM, de Muckadell OS, et al. High-dose ursodeoxycholic acid in primary sclerosing cholangitis: a 5-year multicenter, randomized, controlled study. Gastroenterology. 2005;129:1464-72.

104. Chapman R, Fevery J, Kalloo A, et al. Diagnosis and management of primary sclerosing cholangitis. Hepatology. 2010;51:660-78.

105. European Association for the Study of the Liver. EASL clinical practice guidelines: management of cholestatic liver diseases. J Hepatol. 2009;51:237-67.

106. Svoboda P, Kantorova I, Ochmann J, et al. A prospective randomized controlled trial of sclerotherapy vs ligation in the prophylactic treatment of high-risk esophageal varices. Surg Endosc. 1999;13:580-4.

107. Gotoh Y, Iwakiri R, Sakata Y, et al. Evaluation of endoscopic variceal ligation in prophylactic therapy for bleeding of oesophageal varices: a prospective, controlled trial compared with endoscopic injection sclerotherapy. J Gastroenterol Hepatol. 1999;14:241-4.

108. Triantos C, Vlachogiannakos J, Armonis A, et al. Primary prophylaxis of variceal bleeding in cirrhotics unable to take betablockers: a randomized trial of ligation. Aliment Pharmacol Ther. 2005;21:1435-43.

109. Iso $\mathrm{Y}$, Kawanaka H, Tomikawa M, et al. Repeated injection sclerotherapy is preferable to combined therapy with variceal ligation to avoid recurrence of esophageal varices: a prospective randomized trial. Hepatogastroenterology. 1997;44:467-71.

110. Ideo G, Bellati G, Fesce E, Grimoldi D. Nadolol can prevent the first gastrointestinal bleeding in cirrhotics: a prospective, randomized study. Hepatology. 1988;8:6-9.

111. Garden OJ, Mills PR, Birnie GG, et al. Propranolol in the prevention of recurrent variceal hemorrhage in cirrhotic patients. A controlled trial. Gastroenterology. 1990;98:185-90.

112. Schepke M, Kleber G, Nurnberg D, et al. Ligation versus propranolol for the primary prophylaxis of variceal bleeding in cirrhosis. Hepatology. 2004;40:65-72.

113. Lay CS, Tsai YT, Lee FY, et al. Endoscopic variceal ligation versus propranolol in prophylaxis of first variceal bleeding in patients with cirrhosis. J Gastroenterol Hepatol. 2006;21:413-9.

114. Westaby D, Polson RJ, Gimson AE, et al. A controlled trial of oral propranolol compared with injection sclerotherapy for the long-term management of variceal bleeding. Hepatology. 1990;11:353-9.

115. Sarin SK, Lamba GS, Kumar M, et al. Comparison of endoscopic ligation and propranolol for the primary prevention of variceal bleeding. N Engl J Med. 1999;340:988-93.

116. Jutabha R, Jensen DM, Martin P, et al. Randomized study comparing banding and propranolol to prevent initial variceal hemorrhage in cirrhotics with high-risk esophageal varices. Gastroenterology. 2005;128:870-81.

117. Pérez-Ayuso RM, Valderrama S, Espinoza M, et al. Endoscopic band ligation versus propranolol for the primary prophylaxis of variceal bleeding in cirrhotic patients with high risk esophageal varices. Ann Hepatol. 2010;9:15-22.

118. Funakoshi N, Duny Y, Valats JC, et al. Meta-analysis: betablockers versus banding ligation for primary prophylaxis of esophageal variceal bleeding. Ann Hepatol. 2012;11:369-83.

119. Villanueva C, Balanzo J, Novella MT, et al. Nadolol plus isosorbide mononitrate compared with sclerotherapy for the prevention of variceal rebleeding. $\mathrm{N}$ Engl $\mathrm{J}$ Med. 1996;334:1624-9.

120. Villanueva C, Minana J, Ortiz J, et al. Endoscopic ligation compared with combined treatment with nadolol and isosorbide mononitrate to prevent recurrent variceal bleeding. N Engl J Med. 2001;345:647-55.

121. Lo GH, Chen WC, Chen MH, et al. Banding ligation versus nadolol and isosorbide mononitrate for the prevention of esophageal variceal rebleeding. Gastroenterology. 2002;123:728-34.

122. Wang HM, Lo GH, Chen WC, et al. Comparison of endoscopic variceal ligation and nadolol plus isosorbide-5-mononitrate in the prevention of first variceal bleeding in cirrhotic patients. J Chin Med Assoc. 2006;69:453-60.

123. Li L, Yu C, Li Y. Endoscopic band ligation versus pharmacological therapy for variceal bleeding in cirrhosis: a meta-analysis. Can J Gastroenterol. 2011;25:147-55.

124. Panes J, Bordas JM, Pique JM, et al. Effects of propranolol on gastric mucosal perfusion in cirrhotic patients with portal hypertensive gastropathy. Hepatology. 1993;17:213-8.

125. Perez-Ayuso RM, Pique JM, Bosch J, et al. Propranolol in prevention of recurrent bleeding from severe portal hypertensive gastropathy in cirrhosis. Lancet. 1991;337:1431-4.

126. Lo GH, Lai KH, Cheng JS, et al. The effects of endoscopic variceal ligation and propranolol on portal hypertensive gastropathy: a prospective, controlled trial. Gastrointest Endosc. 2001;53:579-84.

127. Wells M, Chande N, Adams P, et al. Meta-analysis: vasoactive medications for the management of acute variceal bleeds. Aliment Pharmacol Ther. 2012;35:1267-78.

128. D’Amico G, Pagliaro L, Pietrosi G, Tarantino I. Emergency sclerotherapy versus vasoactive drugs for bleeding oesophageal varices in cirrhotic patients. Cochrane Database Syst Rev. 2010. doi:10.1002/14651858.

129. Liu JS, Liu J. Comparison of emergency endoscopic variceal ligation plus octride or octride alone for acute esophageal variceal bleeding. Chin Med J (Engl). 2009;122:3003-6.

130. Sarin SK, Jain AK, Jain M, Gupta R. A randomized controlled trial of cyanoacrylate versus alcohol injection in patients with isolated fundic varices. Am J Gastroenterol. 2002;97:1010-5.

131. Lo GH, Lai KH, Cheng JS, et al. A prospective, randomized trial of butyl cyanoacrylate injection versus band ligation in the management of bleeding gastric varices. Hepatology. 2001;33:1060-4.

132. Tan PC, Hou MC, Lin HC, et al. A randomized trial of endoscopic treatment of acute gastric variceal hemorrhage: N-butyl2-cyanoacrylate injection versus band ligation. Hepatology. 2006;43:690-7.

133. Mishra SR, Chander Sharma B, Kumar A, Sarin SK. Endoscopic cyanoacrylate injection versus beta-blocker for secondary prophylaxis of gastric variceal bleed: a randomised controlled trial. Gut 2010;59:729-35.

134. Mishra SR, Sharma BC, Kumar A, Sarin SK. Primary prophylaxis of gastric variceal bleeding comparing cyanoacrylate injection and beta-blockers: a randomized controlled trial. J Hepatol. 2011;54:1161-7.

135. Iwase H, Shimada M, Tsuzuki T, Hirashima N. Long-term results of endoscopic obliteration with cyanoacrylate glue for gastric fundal variceal bleeding: a 17-year experience. Japanese Journal of Portal Hypertension. 2011;17:137-44. 
136. Kanagawa H, Mima S, Kouyama H, et al. Treatment of gastric fundal varices by balloon-occluded retrograde transvenous obliteration. J Gastroenterol Hepatol. 1996;11:51-8.

137. Hong $\mathrm{CH}$, Kim HJ, Park JH, et al. Treatment of patients with gastric variceal hemorrhage: endoscopic N-butyl-2-cyanoacrylate injection versus balloon-occluded retrograde transvenous obliteration. J Gastroenterol Hepatol. 2009;24:372-8.

138. Akahoshi T, Tomikawa M, Kamori M, et al. Impact of balloonoccluded retrograde transvenous obliteration on management of isolated fundal gastric variceal bleeding. Hepatol Res. 2012;42:385-93.

139. Akahoshi T, Hashizume M, Tomikawa M, et al. Long-term results of balloon-occluded retrograde transvenous obliteration for gastric variceal bleeding and risky gastric varices: a 10-year experience. J Gastroenterol Hepatol. 2008;23:1702-9.

140. Moore KP, Aithal GP. Guidelines on the management of ascites in cirrhosis. Gut 2006;55;Suppl 6:vi1-12.

141. Gauthier A, Levy VG, Quinton A, et al. Salt or no salt in the treatment of cirrhotic ascites: a randomised study. Gut. 1986;27:705-9.

142. Bernardi M, Laffi G, Salvagnini M, et al. Efficacy and safety of the stepped care medical treatment of ascites in liver cirrhosis: a randomized controlled clinical trial comparing two diets with different sodium content. Liver. 1993;13:156-62.

143. Gentilini P, Casini-Raggi V, Di Fiore G, et al. Albumin improves the response to diuretics in patients with cirrhosis and ascites: results of a randomized, controlled trial. J Hepatol. 1999;30:639-45.

144. Bernardi M, Caraceni P, Navickis RJ, Wilkes MM. Albumin infusion in patients undergoing large-volume paracentesis: a meta-analysis of randomized trials. Hepatology. 2012;55:1172-81.

145. Salerno F, Camma C, Enea M, et al. Transjugular intrahepatic portosystemic shunt for refractory ascites: a meta-analysis of individual patient data. Gastroenterology. 2007;133:825-34.

146. Sort P, Navasa M, Arroyo V, et al. Effect of intravenous albumin on renal impairment and mortality in patients with cirrhosis and spontaneous bacterial peritonitis. $\mathrm{N}$ Engl $\mathrm{J}$ Med. 1999;341:403-9.

147. Angeli P, Fasolato S, Mazza E, et al. Combined versus sequential diuretic treatment of ascites in non-azotaemic patients with cirrhosis: results of an open randomised clinical trial. Gut. 2010;59:98-104.

148. European Association for the Study of the Liver. EASL clinical practice guidelines on the management of ascites, spontaneous bacterial peritonitis, and hepatorenal syndrome in cirrhosis. J Hepatol. 2010;53:397-417.

149. Runyon BA, AASLD. Management of adult patients with ascites due to cirrhosis: Update 2012. Hepatology February 2013:1-26.

150. Sakaida I, Kawazoe S, Kajimura K, et al. Tolvaptan for improvement of hepatic edema: a phase 3, multicenter, randomized, double-blind, placebo-controlled trial. Hepatol Res. 2014;44:73-82.

151. Okita K, Kawazoe S, Hasebe C, et al. Dose-finding trial of tolvaptan in liver cirrhosis patients with hepatic edema: a randomized, double-blind, placebo-controlled trial. Hepatol Res. 2014;44:83-91.

152. Sakaida I, Yanase M, Kobayashi Y, et al. The pharmacokinetics and pharmacodynamics of tolvaptan in patients with liver cirrhosis with insufficient response to conventional diuretics: a multicentre, double-blind, parallel-group, phase III study. J Int Med Res. 2012;40:2381-93.

153. Tsien CD, Rabie R, Wong F. Acute kidney injury in decompensated cirrhosis. Gut. 2013;62:131-7.

154. Angeli P, Gines P, Wong F, et al. Diagnosis and management of acute kidney injury in patients with cirrhosis: revised consensus recommendations of the International Club of Ascites. Gut. 2015;64:531-7.

155. Gines P, Arroyo V, Quintero E, et al. Comparison of paracentesis and diuretics in the treatment of cirrhotics with tense ascites. Results of a randomized study. Gastroenterology. 1987;93:234-41.

156. Pozzi M, Osculati G, Boari G, et al. Time course of circulatory and humoral effects of rapid total paracentesis in cirrhotic patients with tense, refractory ascites. Gastroenterology. 1994;106:709-19.

157. Luca A, Feu F, Garcia-Pagan JC, et al. Favorable effects of total paracentesis on splanchnic hemodynamics in cirrhotic patients with tense ascites. Hepatology. 1994;20:30-3.

158. Gines A, Fernandez-Esparrach G, Monescillo A, et al. Randomized trial comparing albumin, dextran 70 , and polygeline in cirrhotic patients with ascites treated by paracentesis. Gastroenterology. 1996;111:1002-10.

159. Sola-Vera J, Minana J, Ricart E, et al. Randomized trial comparing albumin and saline in the prevention of paracentesisinduced circulatory dysfunction in cirrhotic patients with ascites. Hepatology. 2003;37:1147-53.

160. Sola R, Vila MC, Andreu M, et al. Total paracentesis with dextran 40 vs diuretics in the treatment of ascites in cirrhosis: a randomized controlled study. J Hepatol. 1994;20:282-8.

161. Graziotto A, Rossaro L, Inturri P, et al. Reinfusion of concentrated ascitic fluid versus total paracentesis. A randomized prospective trial. Dig Dis Sci. 1997;42:1708-14.

162. Zaak D, Paquet KJ, Kuhn R. Prospective study comparing human albumin vs. reinfusion of ultrafiltrate-ascitic fluid after total paracentesis in cirrhotic patients with tense ascites. Z Gastroenterol. 2001;39:5-10.

163. Dumortier J, Pianta E, Le Derf Y, et al. Peritoneovenous shunt as a bridge to liver transplantation. Am $\mathbf{J}$ Transplant. 2005;5:1886-92.

164. Rosemurgy AS, Zervos EE, Clark WC, et al. TIPS versus peritoneovenous shunt in the treatment of medically intractable ascites: a prospective randomized trial. Ann Surg 2004;239:883-9; discussion 889-91.

165. Stanley MM, Ochi S, Lee KK, et al. Peritoneovenous shunting as compared with medical treatment in patients with alcoholic cirrhosis and massive ascites. $\mathrm{N}$ Engl $\mathrm{J}$ Med. 1989;321:1632-8.

166. Gines P, Arroyo V, Vargas V, et al. Paracentesis with intravenous infusion of albumin as compared with peritoneovenous shunting in cirrhosis with refractory ascites. N Engl J Med. 1991;325:829-35.

167. Deltenre P, Mathurin P, Dharancy S, et al. Transjugular intrahepatic portosystemic shunt in refractory ascites: a meta-analysis. Liver Int. 2005;25:349-56.

168. Saab S, Nieto JM, Lewis SK, Runyon BA. TIPS versus paracentesis for cirrhotic patients with refractory ascites. Cochrane Database Syst Rev. 2006. doi:10.1002/14651858.

169. Albillos A, Banares R, Gonzalez M, et al. A meta-analysis of transjugular intrahepatic portosystemic shunt versus paracentesis for refractory ascites. J Hepatol. 2005;43:990-6.

170. D'Amico G, Luca A, Morabito A, et al. Uncovered transjugular intrahepatic portosystemic shunt for refractory ascites: a metaanalysis. Gastroenterology. 2005;129:1282-93.

171. Thalheimer U, Leandro G, Samonakis DN, et al. TIPS for refractory ascites: a single-centre experience. J Gastroenterol. 2009;44:1089-95.

172. Maleux G, Perez-Gutierrez NA, Evrard S, et al. Covered stents are better than uncovered stents for transjugular intrahepatic portosystemic shunts in cirrhotic patients with refractory ascites: a retrospective cohort study. Acta Gastroenterol Belg. 2010;73:336-41. 
173. Bai M, Qi XS, Yang ZP, et al. TIPS improves liver transplantation-free survival in cirrhotic patients with refractory ascites: an updated meta-analysis. World J Gastroenterol. 2014;20:2704-14.

174. Saab S, Nieto JM, Ly D, Runyon BA. TIPS versus paracentesis for cirrhotic patients with refractory ascites. Cochrane Database Syst Rev. 2004. doi:10.1002/14651858.

175. Campbell MS, Brensinger CM, Sanyal AJ, et al. Quality of life in refractory ascites: transjugular intrahepatic portal-systemic shunting versus medical therapy. Hepatology. 2005;42:635-40.

176. Arvaniti V, D'Amico G, Fede G, et al. Infections in patients with cirrhosis increase mortality four-fold and should be used in determining prognosis. Gastroenterology 2010;139:1246-56.e5.

177. Chavez-Tapia NC, Barrientos-Gutierrez T, Tellez-Avila FI, et al. Antibiotic prophylaxis for cirrhotic patients with upper gastrointestinal bleeding. Cochrane Database Syst Rev. 2010. doi:10.1002/14651858.

178. Chavez-Tapia NC, Barrientos-Gutierrez T, Tellez-Avila F, et al. Meta-analysis: antibiotic prophylaxis for cirrhotic patients with upper gastrointestinal bleeding - an updated Cochrane review. Aliment Pharmacol Ther. 2011;34:509-18.

179. Fernandez J, Navasa M, Planas R, et al. Primary prophylaxis of spontaneous bacterial peritonitis delays hepatorenal syndrome and improves survival in cirrhosis. Gastroenterology. 2007;133:818-24.

180. Loomba R, Wesley R, Bain A, et al. Role of fluoroquinolones in the primary prophylaxis of spontaneous bacterial peritonitis: meta-analysis. Clin Gastroenterol Hepatol. 2009;7:487-93.

181. Salerno F, Gerbes A, Gines P, et al. Diagnosis, prevention and treatment of hepatorenal syndrome in cirrhosis. Gut. 2007;56:1310-8.

182. Fabrizi F, Dixit V, Messa P, Martin P. Terlipressin for hepatorenal syndrome: a meta-analysis of randomized trials. Int $\mathrm{J}$ Artif Organs. 2009;32:133-40.

183. Sagi SV, Mittal S, Kasturi KS, Sood GK. Terlipressin therapy for reversal of type 1 hepatorenal syndrome: a meta-analysis of randomized controlled trials. J Gastroenterol Hepatol. 2010;25:880-5.

184. Gluud LL, Christensen K, Christensen E, Krag A. Terlipressin for hepatorenal syndrome. Cochrane Database Syst Rev. 2012;(9):CD005162.

185. Skagen C, Einstein M, Lucey MR, Said A. Combination treatment with octreotide, midodrine, and albumin improves survival in patients with type 1 and type 2 hepatorenal syndrome. J Clin Gastroenterol. 2009;43:680-5.

186. Alessandria C, Ottobrelli A, Debernardi-Venon W, et al. Noradrenalin vs terlipressin in patients with hepatorenal syndrome: a prospective, randomized, unblinded, pilot study. J Hepatol. 2007;47:499-505.

187. Singh V, Ghosh S, Singh B, et al. Noradrenaline vs. terlipressin in the treatment of hepatorenal syndrome: a randomized study. J Hepatol. 2012;56:1293-8.

188. Ghosh S, Choudhary NS, Sharma AK, et al. Noradrenaline vs terlipressin in the treatment of type 2 hepatorenal syndrome: a randomized pilot study. Liver Int. 2013;33:1187-93.

189. Linas SL, Schaefer JW, Moore EE, et al. Peritoneovenous shunt in the management of the hepatorenal syndrome. Kidney Int. 1986;30:736-40.

190. Scholz DG, Nagorney DM, Lindor KD. Poor outcome from peritoneovenous shunts for refractory ascites. Am J Gastroenterol. 1989;84:540-3.

191. Guevara M, Gines P, Bandi JC, et al. Transjugular intrahepatic portosystemic shunt in hepatorenal syndrome: effects on renal function and vasoactive systems. Hepatology. 1998;28:416-22.

192. Brensing KA, Textor J, Perz J, et al. Long term outcome after transjugular intrahepatic portosystemic stent-shunt in non- transplant cirrhotics with hepatorenal syndrome: a phase II study. Gut. 2000;47:288-95.

193. Wong F, Pantea L, Sniderman K. Midodrine, octreotide, albumin, and TIPS in selected patients with cirrhosis and type 1 hepatorenal syndrome. Hepatology. 2004;40:55-64.

194. Boyer TD, Sanyal AJ, Garcia-Tsao G, et al. Impact of liver transplantation on the survival of patients treated for hepatorenal syndrome type 1. Liver Transpl. 2011;17:1328-32.

195. Moller S, Krag A, Bendtsen F. Kidney injury in cirrhosis: pathophysiological and therapeutic aspects of hepatorenal syndromes. Liver Int. 2014. doi:10.1111/liv.12549.

196. Cordoba J, Lopez-Hellin J, Planas M, et al. Normal protein diet for episodic hepatic encephalopathy: results of a randomized study. J Hepatol. 2004;41:38-43.

197. Plauth M, Cabre E, Riggio O, et al. ESPEN Guidelines on Enteral Nutrition: liver disease. Clin Nutr. 2006;25:285-94.

198. Sharma BC, Sharma P, Agrawal A, Sarin SK. Secondary prophylaxis of hepatic encephalopathy: an open-label randomized controlled trial of lactulose versus placebo. Gastroenterology 2009;137:885-91.e1.

199. Sharma P, Agrawal A, Sharma BC, Sarin SK. Prophylaxis of hepatic encephalopathy in acute variceal bleed: a randomized controlled trial of lactulose versus no lactulose. J Gastroenterol Hepatol. 2011;26:996-1003.

200. Als-Nielsen B, Gluud LL, Gluud C. Non-absorbable disaccharides for hepatic encephalopathy: systematic review of randomised trials. BMJ. 2004;328:1046.

201. Shukla S, Shukla A, Mehboob S, Guha S. Meta-analysis: the effects of gut flora modulation using prebiotics, probiotics and synbiotics on minimal hepatic encephalopathy. Aliment Pharmacol Ther. 2011;33:662-71.

202. Bass NM, Mullen KD, Sanyal A, et al. Rifaximin treatment in hepatic encephalopathy. N Engl J Med. 2010;362:1071-81.

203. Bajaj JS, Heuman DM, Wade JB, et al. Rifaximin improves driving simulator performance in a randomized trial of patients with minimal hepatic encephalopathy. Gastroenterology. 2011;140:478-87.e1.

204. Eltawil KM, Laryea M, Peltekian K, Molinari M. Rifaximin vs. conventional oral therapy for hepatic encephalopathy: a metaanalysis. World J Gastroenterol. 2012;18:767-77.

205. Sharma BC, Sharma P, Lunia MK, et al. A randomized, doubleblind, controlled trial comparing rifaximin plus lactulose with lactulose alone in treatment of overt hepatic encephalopathy. Am J Gastroenterol. 2013;108:1458-63.

206. Kimer N, Krag A, Moller S, et al. Systematic review with metaanalysis: the effects of rifaximin in hepatic encephalopathy. Aliment Pharmacol Ther. 2014;40:123-32.

207. Plauth M, Cabre E, Campillo B, Kondrup J, Marchesini G, Schutz T, Shenkin A, Wendon J. ESPEN guidelines on parenteral nutrition: hepatology. Clin Nutr. 2009;28:436-44.

208. Als-Nielsen B, Koretz RL, Kjaergard LL, Gluud C. Branchedchain amino acids for hepatic encephalopathy. Cochrane Database Syst Rev 2003.

209. Moriwaki H, Miwa Y, Tajika M, et al. Branched-chain amino acids as a protein- and energy-source in liver cirrhosis. Biochem Biophys Res Commun. 2004;313:405-9.

210. Marchesini G, Bianchi G, Merli M, et al. Nutritional supplementation with branched-chain amino acids in advanced cirrhosis: a double-blind, randomized trial. Gastroenterology. 2003;124:1792-801.

211. Gluud LL, Dam G, Les I, et al. Branched-chain amino acids for people with hepatic encephalopathy. Cochrane Database Syst Rev. 2015;(2):CD001939.

212. Ohmoto K, Miyake I, Tsuduki M, et al. Control of solitary gastric fundal varices and portosystemic encephalopathy accompanying liver cirrhosis by balloon-occluded retrograde 
transvenous obliteration (B-RTO): a case report. Hepatogastroenterology. 1999;46:1249-52.

213. Kato T, Uematsu T, Nishigaki Y, et al. Therapeutic effect of balloon-occluded retrograde transvenous obliteration on portalsystemic encephalopathy in patients with liver cirrhosis. Intern Med. 2001;40:688-91.

214. Miyamoto Y, Oho K, Kumamoto M, et al. Balloon-occluded retrograde transvenous obliteration improves liver function in patients with cirrhosis and portal hypertension. J Gastroenterol Hepatol. 2003;18:934-42.

215. Uehara H, Akahoshi T, Tomikawa M, et al. Prediction of improved liver function after balloon-occluded retrograde transvenous obliteration: relation to hepatic vein pressure gradient. J Gastroenterol Hepatol. 2012;27:137-41.

216. Francoz C, Valla D, Durand F. Portal vein thrombosis, cirrhosis, and liver transplantation. J Hepatol. 2012;57:203-12.

217. Francoz C, Belghiti J, Vilgrain V, et al. Splanchnic vein thrombosis in candidates for liver transplantation: usefulness of screening and anticoagulation. Gut. 2005;54:691-7.

218. Rodriguez-Castro KI, Simioni P, Burra P, Senzolo M. Anticoagulation for the treatment of thrombotic complications in patients with cirrhosis. Liver Int. 2012;32:1465-76.

219. Delgado MG, Seijo S, Yepes I, et al. Efficacy and safety of anticoagulation on patients with cirrhosis and portal vein thrombosis. Clin Gastroenterol Hepatol. 2012;10:776-83.

220. Huard G, Bilodeau M. Management of anticoagulation for portal vein thrombosis in individuals with cirrhosis: a systematic review. Int J Hepatol. 2012;2012:672986.

221. Amin MA, el-Gendy MM, Dawoud IE, et al. Partial splenic embolization versus splenectomy for the management of hypersplenism in cirrhotic patients. World J Surg 2009;33:1702-10.

222. Quintini C, D’Amico G, Brown C, et al. Splenic artery embolization for the treatment of refractory ascites after liver transplantation. Liver Transpl. 2011;17:668-73.

223. Kim H, Suh KS, Jeon YM, et al. Partial splenic artery embolization for thrombocytopenia and uncontrolled massive ascites after liver transplantation. Transplant Proc. 2012;44:755-6.

224. Smith M, Ray CE. Splenic artery embolization as an adjunctive procedure for portal hypertension. Semin Interv Radiol. 2012;29:135-9.
225. Yoshida H, Mamada Y, Taniai N, et al. Long-term results of partial splenic artery embolization as supplemental treatment for portal-systemic encephalopathy. Am J Gastroenterol. 2005;100:43-7.

226. Imura S, Shimada M, Utsunomiya $T$, et al. Impact of splenectomy in patients with liver cirrhosis: results from 18 patients in a single center experience. Hepatol Res. 2010;40:894-900.

227. Zhou J, Wu Z, Wu J, et al. Laparoscopic splenectomy plus preoperative endoscopic variceal ligation versus splenectomy with pericardial devascularization (Hassab's operation) for control of severe varices due to portal hypertension. Surg Endosc. 2013;27:4371-7.

228. Xu RY, Liu B, Lin N. Therapeutic effects of endoscopic variceal ligation combined with partial splenic embolization for portal hypertension. World J Gastroenterol. 2004;10:1072-4.

229. Merion RM, Schaubel DE, Dykstra DM, et al. The survival benefit of liver transplantation. Am J Transplant. 2005;5:307-13.

230. Sharma P, Schaubel DE, Guidinger MK, Merion RM. Effect of pretransplant serum creatinine on the survival benefit of liver transplantation. Liver Transpl. 2009;15:1808-13.

231. Ishigami M, Honda T, Okumura A, et al. Use of the Model for End-Stage Liver Disease (MELD) score to predict 1-year survival of Japanese patients with cirrhosis and to determine who will benefit from living donor liver transplantation. J Gastroenterol. 2008;43:363-8.

232. Samuel D, Muller R, Alexander G, et al. Liver transplantation in European patients with the hepatitis B surface antigen. N Engl J Med. 1993;329:1842-7.

233. Gane E. The natural history and outcome of liver transplantation in hepatitis $\mathrm{C}$ virus-infected recipients. Liver Transpl. 2003;9:S28-34.

234. Cholongitas E, Goulis J, Akriviadis E, Papatheodoridis GV. Hepatitis B immunoglobulin and/or nucleos(t)ide analogues for prophylaxis against hepatitis $b$ virus recurrence after liver transplantation: a systematic review. Liver Transpl. 2011;17:1176-90.

235. Carrion JA, Navasa M, Garcia-Retortillo M, et al. Efficacy of antiviral therapy on hepatitis $\mathrm{C}$ recurrence after liver transplantation: a randomized controlled study. Gastroenterology. 2007;132:1746-56. 